OECD Health Working Papers No. 91

\title{
An OECD analysis of health spending in Norway
}

\author{
David Morgan,
}

Michael Gmeinder,

Jens Wilkens 
Organisation de Coopération et de Développement Économiques

Organisation for Economic Co-operation and Development

09-Jan-2017

DIRECTORATE FOR EMPLOYMENT, LABOUR AND SOCIAL AFFAIRS

English text only

HEALTH COMMITTEE

\section{Health Working Papers}

OECD Health Working Paper No. 91

AN OECD ANALYSIS OF HEALTH SPENDING IN NORWAY

David Morgan, Michael Gmeinder, Jens Wilkens*

JEL classification: 118

Authorized for publication by Stefano Scarpetta, Director, Directorate for Employment, Labour and Social Affairs

(*) OECD, Directorate for Employment, Labour and Social Affairs, Health Division.

All health Working Papers are now available through the OECD's website at: http://www.oecd.org/els/health-systems/health-working-papers.htm

JT03407577

Complete document available on OLIS in its original format

This document and any map included herein are without prejudice to the status of or sovereignty over any territory, to the delimitation of international frontiers and boundaries and to the name of any territory, city or area. 


\title{
DIRECTORATE FOR EMPLOYMENT, LABOUR AND SOCIAL AFFAIRS
}

\author{
www.oecd.org/els
}

\section{OECD HEALTH WORKING PAPERS}

\author{
http://www.oecd.org/els/health-systems/health-working-papers.htm
}

OECD Working Papers should not be reported as representing the official views of the OECD or of its member countries. The opinions expressed and arguments employed are those of the author(s).

Working Papers describe preliminary results or research in progress by the author(s) and are published to stimulate discussion on a broad range of issues on which the OECD works. Comments on Working Papers are welcomed, and may be sent to the Directorate for Employment, Labour and Social Affairs OECD, 2 rue André-Pascal, 75775 Paris Cedex 16, France.

This series is designed to make available to a wider readership selected health studies prepared for use within the OECD. Authorship is usually collective, but principal writers are named. The papers are generally available only in their original language - English or French - with a summary in the other.

This document and any map included herein are without prejudice to the status of or sovereignty over any territory, to the delimitation of international frontiers and boundaries and to the name of any territory, city or area.

The statistical data for Israel are supplied by and under the responsibility of the relevant Israeli authorities. The use of such data by the OECD is without prejudice to the status of the Golan Heights, East Jerusalem and Israeli settlements in the West Bank under the terms of international law.

You can copy, download or print OECD content for your own use, and you can include excerpts from OECD publications, databases and multimedia products in your own documents, presentations, blogs, websites and teaching materials, provided that suitable acknowledgment of OECD as source and copyright owner is given. All requests for commercial use and translation rights should be submitted to rights@oecd.org. 


\begin{abstract}
Norway is one of the top spenders on health care among OECD countries in per capita terms but much closer to the average when seen as a share of GDP. The question is to what extent these two key measures are compatible, and how Norway really measures up to other relevant high-income countries in health spending. In considering the latter, Norway allocates more to long-term care services than any other country. So how comparable are countries in the measurement of sectors such as long-term care and does this play a key role in determining overall spending estimates?

Delving further, how does spending on the key sector of somatic specialist health care compared to other countries? If too much is spent, there is a risk that there is an over-emphasis on hospitals compared to primary care. On the other hand if there are too little resources in hospitals, there may be an overexpectation from the sector. However, estimates of spending based on inpatient care still mask a number of organisational and accounting differences, requiring adjustments to be made to the underlying figures. The resulting figures provide a new insight into cross-country comparisons and trends of somatic hospital spending.

Finally, to determine what is explaining the different levels of spending, the appropriate use of international spatial deflators is discussed. Recent advances in the methodology to compile comparative price information for the health and hospital sectors are used to reveal to what extent spending across the comparator countries is the result of price or volume effects.
\end{abstract}

\title{
RÉSUMÉ
}

La Norvège est l'un des pays qui dépense le plus pour les soins de santé dans les pays de l'OCDE par habitant, mais ce pays est beaucoup plus proche de la moyenne quand on regarde ces dépenses de santé en proportion du PIB. La question est de savoir si ces deux mesures clés sont compatibles et comment la Norvège se compare réellement par rapport aux autres pays à niveaux de dépenses de santé élevés. Si l'on prend en compte ce dernier point, la Norvège alloue davantage aux soins de longue durée que tout autre pays. On peut ainsi se demander si les pays sont comparables quand il s'agit des dépenses en soins de longue durée et dans quelle mesure cette comparabilité joue un rôle dans l'estimation globale des dépenses?

On peut également se demander comment compare-t-on les dépenses clés relatives aux soins somatiques spécialisés par rapport à d'autres pays ? Si l'on dépense trop, il y a un risque d'accorder une place trop importante aux hôpitaux par rapport aux soins primaires. D'autre part, s'il y a trop peu de ressources dans les hôpitaux, il peut y avoir des attentes trop fortes sur le secteur. Toutefois, les estimations des dépenses fondées sur les soins hospitaliers cachent encore un certain nombre de différences organisationnelles et comptables, nécessitant d'apporter des ajustements aux chiffres sous-jacents. Les chiffres qui en résultent fournissent un nouvel aperçu des comparaisons entre pays et des tendances des dépenses somatiques dans les hôpitaux.

Enfin, pour déterminer ce qui explique les différents niveaux de dépenses, l'utilisation appropriée des déflateurs spatiaux internationaux est examinée. Les progrès récents des méthodologies permettant de compiler l'information comparative sur les prix pour les secteurs de la santé et des hôpitaux sont utilisés pour révéler dans quelle mesure les dépenses dans les pays comparateurs sont le résultat d'un effet prix ou d'un effet volume. 


\section{TABLE OF CONTENTS}

ABSTRACT

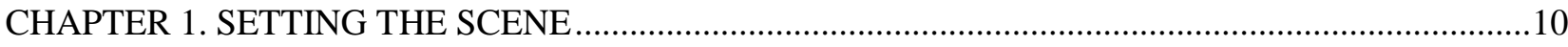

Norway is one of the highest per capita spenders on health ...............................................................10

Understanding international measures of health spending ...................................................................11

CHAPTER 2. UNRAVELLING AGGREGATE HEALTH SPENDING …..............................................13

Norway's level of wealth means that it is a high spender on health care ...............................................13

Health as a share of GDP in Norway is lower than other countries due to its oil and gas production.......14

Norway allocates a similar share of government spending to health as its neighbours ...........................15

Comparing health spending by type of care provides a better insight ...................................................17

Spending on long-term care is a key component of health spending in high-income countries ................19

Most countries have seen health spending fall as a result of the economic crisis..................................21

CHAPTER 3. A BETTER MEASURE OF HOSPITAL INPATIENT SPENDING ...................................24

International estimates of inpatient care are affected by the different organisation of mental health among

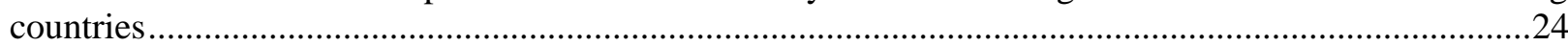

Norway spends more per capita on somatic care but a similar share of health spending as its neighbours 26 Spending on mental health/substance abuse continues to grow while volumes appear to have fallen .......28

CHAPTER 4. NORWEGIANS PAY A HIGHER PRICE FOR HEALTH CARE.......................................31

High price levels in the Norwegian health sector help explain the level of health spending....................31

Adjusting for high hospital prices means Norwegians consume relatively less ........................................34

High salaries and staffing levels can help explain higher prices ..........................................................35

Long lengths of stay in Germany and Switzerland can help explain high volumes ................................37

Norway's use of day surgery as a way to reduce costs is relatively low ..................................................40

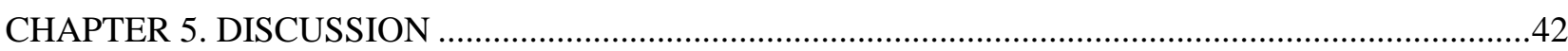

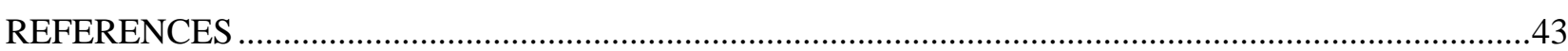

\section{Tables}

Table 1. GDP per capita and health spending, 2015 ..................................................................16

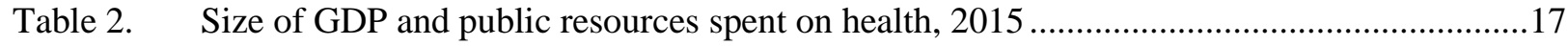

Table 3. Health spending on selected functions of health care, 2014 .............................................19

Table 4. Annual average growth in per capita health spending for selected functions of health care,

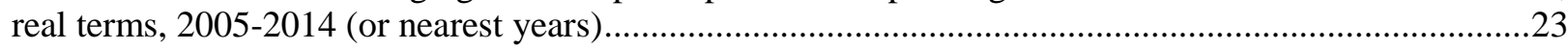

Table 5. Share of hospital employment (FTE) by type of profession, 2014 ….................................36

Table 6. Comparison of ALOS reduction for selected diagnose groups, 2004-2014 ….....................40 


\section{Figures}

Figure 1. Health expenditure as a share of GDP, OECD countries, 2015 ......................................10

Figure 2. Health expenditure per capita, OECD countries, 2015 ..................................................11

Figure 3. Per capita health spending and GDP in OECD countries, 2015 .....................................13

Figure 4. Health spending per capita and as a share of GDP, 2015 ................................................14

Figure 5. Current health spending and GDP, Norway 2010-2015 …...........................................15

Figure 6. Current health expenditure by function of care, OECD countries, 2014 (or nearest year)....18

Figure 7. Long-term care workers per 100 people aged 65 and over, 2013 (or nearest year) .............20

Figure 8. Per capita health spending and LTC share, OECD countries, 2014 ..................................21

Figure 9. Annual average growth in per capita health spending, real terms*, 2005-2014 (or nearest

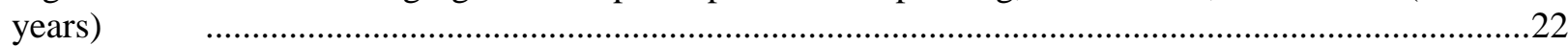

Figure 10. From unadjusted hospital inpatient care to somatic hospital inpatient care ....................25

Figure 11. Per capita spending on (somatic) hospital inpatient care, 2013 ......................................27

Figure 12. Somatic hospital inpatient spending as a share of all spending on individual health care

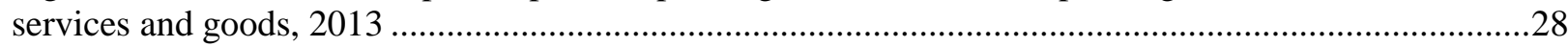

Figure 13. Trends in hospital inpatient spending, nominal terms*, 2005-2013 _.............................29

Figure 14. Annual growth in bed-days, expenditure per bed-day and total expenditure for mental

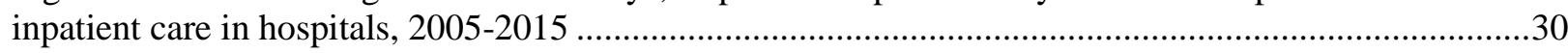

Figure 15. Price level indices (PLI) for GDP, health and hospital services, 2015, EU28=100 ...........32

Figure 16. Comparison of per capita volume indices for health, 2015. Norway $=100 \ldots \ldots \ldots \ldots \ldots \ldots \ldots . . . . . . . . . .33$

Figure 17. Comparison of per capita volume indices for hospital care, 2013. Norway=100..............34

Figure 18. Hospital beds per 1000 population, 2013 (or nearest year) ............................................37

Figure 19. Curative care discharges for selected diagnose groups per 1000 population, 2014 ...........38

Figure 20. Comparison of ALOS for selected diagnose groups, 2014 .............................................39

Figure 21. Proportion of procedures performed as day surgery for selected surgeries, 2014 (or

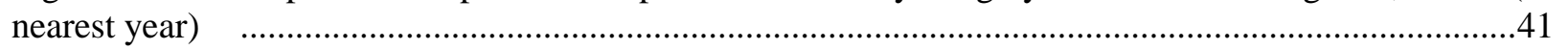




\section{ACKNOWLEDGEMENTS}

The authors would like to express their appreciation to Tone Hobæk (Ministry of Health and Care Services, Norway) and Hans Olav Melberg (University of Oslo) for their overall guidance and participation in the study, in addition to Jeanette Øynes and Kjersti Hernæs (Statistics Norway). Particular thanks are also given to Mads Bager Hoffman (Ministry of Health, Denmark), Fredrik Nilsson (Statistics Sweden), Vincent van Polanen Petel (Statistics Netherlands), Moritz Mannschreck (Federal Statistics Office, Germany), Raymond Rossel (Federal Statistical Office, Switzerland) and Lisbeth Serdén (The National Board of Health and Welfare, Sweden) for their invaluable help and assistance.

The authors would also like to acknowledge the useful comments from Ane Auraaen, Luca Lorenzoni and Michael Mueller of the OECD Health Division. 


\section{EXECUTIVE SUMMARY}

1. The amount that a country spends on health care for its population and how this changes over time is the result of a wide array of social, demographic and economic factors, as well as the financing and organisational structure of a country's health system. Differences between countries in what they spend can depend on such variables as the level of income, the population structure, disease patterns, the supply and use of technology and resources, the price levels in the health sector itself and, of course, the priority that both governments and individuals place on health.

2. The two most common international comparative indicators of health spending - per capita expenditure and expenditure as a share of gross domestic product (GDP) - show Norway to be one of the highest spenders among OECD countries in per capita terms but only around average when measured as a share of GDP. In this context, the OECD Health Division conducted a study to examine the comparability of health spending estimates in Norway with five other high-income OECD countries, focussing on the measurement of overall health spending and its principal components, with the objective of deriving a clearer interpretation of the above indicators. As part of the analysis, particular attention was paid to spending on somatic (inpatient) hospital care, which constitutes a large part of overall health expenditure, and for which more detailed data on prices and volumes are available.

3. In undertaking the analysis, the study leverages on existing health accounts data and methodological information, as well as additional data collected on expenditures, prices, activities and resources in the health sector from both national and international sources.

4. It is important to note that the purpose of the report is not on whether Norway spends "too much or too little" on any type of health care or whether Norway gets value for the money it spends. Rather it focuses on the correct measurement of health care spending and strives to explain some of the possible factors behind the observed differences.

\section{Key findings are:}

5. The estimates of current health spending for Norway and the five comparator countries (Denmark, Germany, the Netherlands, Sweden and Switzerland), as submitted and validated under the annual health accounts data collection of the OECD, the European Commission and the WHO, are considered to be sufficiently in line with international definitions and boundaries to provide for a meaningful comparative measure of overall health spending across the six countries.

6. Compared with the other five high-income countries, Norway has the highest per capita income, the highest life expectancy at birth but the lowest proportion of the population over 65. As such, overall per capita health spending (adjusted for differences in general price levels) observed for Norway (the fourth highest of all OECD countries in 2014) is considered generally in line with its level of wealth and demographic structure.

7. The share of an economy's resources (measured as GDP) allocated to health care is dependent both on the overall wealth of the country as well as the spending on health at any point in time. The change in the ratio is therefore dependent on trends in both. In line with its Nordic neighbours, Norway relies heavily on public resources to fund the health sector. Therefore, while the share of government expenditure allocated to health is similar, the size of the public sector overall in relation to the economy is highly dependent on its oil and gas production, which can explain the lower share of GDP. The resulting disparity between per capita spending and the share of GDP is mirrored in other public-funded sectors, such as education. 
8. Long-term care (LTC) spending differences between countries are driven by income, dependency levels and the provision of formal care in institutional or home settings. Among the six comparator countries, estimates of LTC are considered to be generally comparable ${ }^{1}$ (in contrast to a number of other OECD countries). Based on the level of wealth, the number of dependents and the high labour participation rate (taken as a proxy for the need for formal care), the share of health spending allocated to LTC observed in Norway is in line with expectations.

9. The comparability of hospital inpatient care spending estimates can be affected by both data limitations as well as organisational differences across the countries. In this study, adjustments are made for differences in the accounting of mental care and substance abuse services, as well as day care and ancillary services. Additional data and clarifications gathered from national experts provide a more homogeneous category of somatic hospital inpatient care spending. In per capita terms and adjusted for general price differences between countries, it is estimated that Norway spends around $10 \%$ more on per capita somatic hospital care than Germany, Denmark and the Netherlands, and around $30 \%$ more than Sweden. Yet, when looked at as a share of all curative and rehabilitative health care spending ${ }^{2}$, the six countries allocate roughly the same proportion - around a third of the total - to spending on somatic hospital care.

10. However, available data suggest that comparative price levels covering only the health and hospital sectors are much higher in Norway than in the other countries (except Switzerland). The health (and hospital) sector is a highly labour intensive sector. Limited data collected by OECD from national sources suggest that staff costs may play a more important role in the hospital cost structure in Norway than in some of the other comparator countries. Data on human resources from OECD Health Statistics points towards a higher density of professional staff (physicians and nurses) in hospitals in Norway rather simply remuneration levels as an important driver of overall staff costs in Norway.

11. As a result, when overall per capita health spending is deflated using health-specific prices, the per capita consumption of health services is more equal, with volumes in Norway at around the same level as in Denmark and the Netherlands, around $10 \%$ below that of Germany and Switzerland, but still higher than in Sweden.

12. Similarly, applying hospital-specific prices to the adjusted hospital spending figures results in Norway having the lowest per capita volume of somatic hospital services apart from Sweden, and much lower than in Denmark (although further analysis of the low hospital price levels reported for Denmark is recommended). This suggests that the relatively high hospital prices in Norway (and Switzerland) help explain the overall level of hospital spending.

13. The higher volume of care in hospitals in Germany and Switzerland tends to be corroborated by data showing longer lengths of stay and higher rates of discharges for Germany in particular. Norway has just above average number of discharges but below average lengths of stay. The higher rates of day surgery and shorter lengths of stay in Denmark may help to explain lower overall hospital costs, but the significantly lower prices in Danish hospitals would require further investigation as to their robustness.

14. All of the countries (except Switzerland) have seen a notable decrease in health spending growth after the global financial crisis as countries took measures to reduce spending in the light of constraints in public funds. The National Health Service based systems (Denmark, Norway and Sweden)

\footnotetext{
1. Previous comparisons between Norway and, for example, Sweden were hampered by differing interpretations of what constitutes long-term care spending, with regards to health and social care. Recent revisions have resulted in more consistent definitions being applied by the countries in this study.

2. Refers to other personal health care services and goods, that is, excluding long-term care and collective services (prevention and administration).
} 
DELSA/HEA/WD/HWP(2017)1

have generally seen growth maintained at a lower level as a consequence of the wider range of budgetary tools available (OECD, 2015a). 


\section{CHAPTER 1. SETTING THE SCENE}

\section{Norway is one of the highest per capita spenders on health}

15. During recent years there has been a national debate as to whether Norway spends more or less on health care compared to other high-income OECD countries. While Norway ranks near the top when it comes to "health expenditure per capita", it is much closer to the OECD average in terms of "health expenditure as a share of gross domestic product (GDP)" - that is, how much of its economy it allocates to spending on health care. Other high-income OECD countries spent 10-12\% of their GDP on health while Norway spent 9.9\% in 2015 (Figure 1). As such, Norway typically features in the second tier of OECD countries in terms of share of GDP and as recently as 2013 spent only around the OECD average. Only one other country, Luxembourg, is more extreme in this respect in that it ranks near the top of OECD countries when health spending is measured in per capita terms, but among the bottom third when looking at the share of GDP.

Figure 1. Health expenditure as a share of GDP, OECD countries, 2015

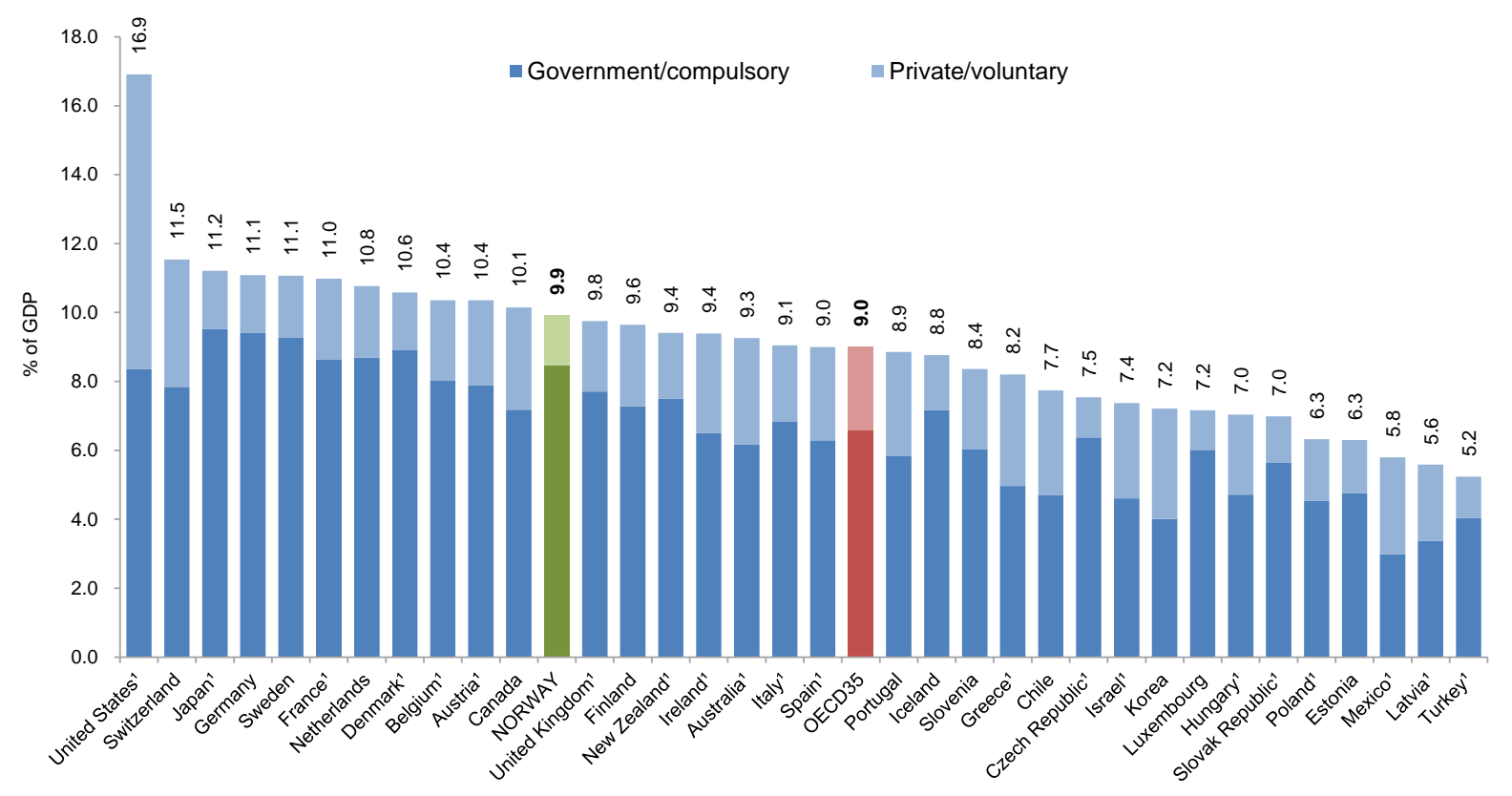

1. OECD estimate.

Source: OECD Health Statistics 2016.

16. Given the link between economic wealth and health spending (Ke et al, 2011), it is perhaps not surprising that Norway ranks high among OECD countries in terms of per capita expenditure on health. In fact, Norway ranked third overall in per capita GDP and fourth in per capita health spending among OECD countries in 2015, when adjusted for differences in overall price levels between countries (Figure 2). At the same time, Norway has a relatively young population, high life expectancy and does generally well with regard to risk factors such as smoking, alcohol and obesity. 
Figure 2. Health expenditure per capita, OECD countries, 2015

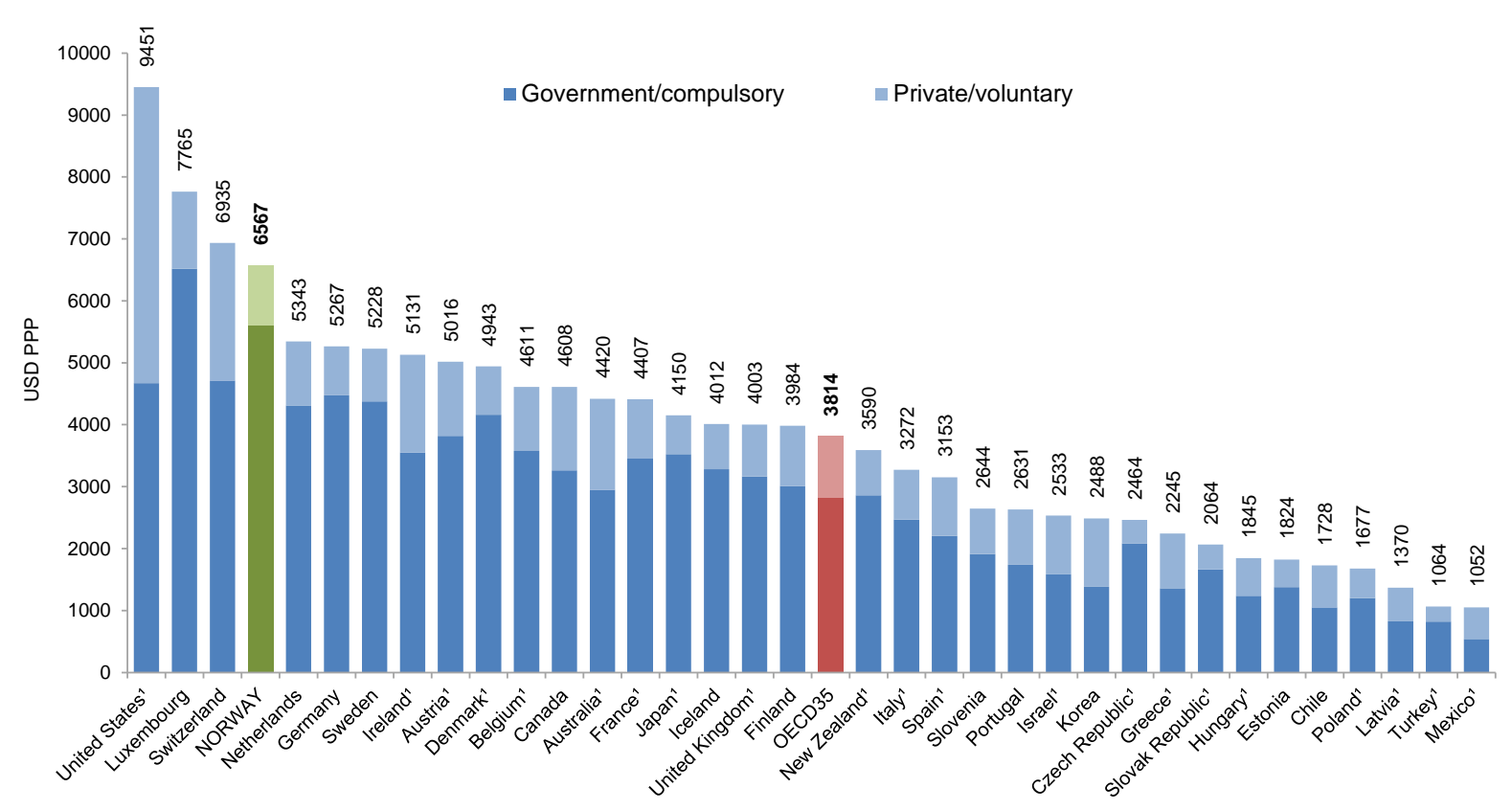

Data adjusted for differences in economy-wide price levels.

1. OECD estimate.

Source: OECD Health Statistics 2016.

\section{Understanding international measures of health spending}

17. In that context, the Norwegian Ministry of Health and Care Services requested the OECD Health Division to examine how health spending in Norway compares with other relevant high-income OECD countries. It is important at this point to make a distinction between this and the question of whether Norway spends "too little" or "too much" on health care. The level of spending of any one country is dependent on many social, demographic and economic factors, as well as political priorities and institutional arrangements; the question as to what is the right level of health spending is thus a difficult one to answer. As such, this study focuses more on the correct measurement of health spending and an explanation of some of the possible factors behind the observed differences, rather than a discussion of what is the correct level of spending, or indeed whether Norway gets value for money for its health spending in terms of better health outcomes.

18. The study analyses and seeks to explain health spending differences in Norway in comparison with five other high-income OECD countries primarily using health accounts data collected by the OECD (under the System of Health Accounts framework). The comparator group covers both countries with health systems that are organised in a similar way to Norway's (e.g. Denmark and Sweden, i.e. National Health Service type systems) as well as countries with different structures of financing and service provision (e.g. Netherlands, Switzerland, Germany, i.e. countries with various forms of compulsory health insurance type systems).

19. In examining any differences in overall health spending (according to international definitions), the boundary of "health care" covering basic care, specialist care and long-term care (LTC), in addition to medical goods and collective services, such as public health and administration is considered. One 
immediate observation when analysing health spending across the OECD is that countries, such as Norway, the Netherlands, Sweden and Denmark, that have more formal arrangements for the elderly and the dependent population, allocate a quarter or more of their overall health spending to long-term care services. The question arises as to whether spending on long-term care itself is a significant factor to explain why these countries are ranked relatively high when it comes to overall health care spending. In that context, it is important to examine spending on the components of health care individually.

20. After considering the contribution of LTC spending to overall health spending, there is a specific interest in analysing and comparing spending on somatic hospital (or inpatient curative) care compared to the other high-income countries: the rationale being that if more is spent in this sector, there is a risk of an over-emphasis on hospital care compared to the primary care sector. On the other hand, if too few resources are allocated to hospitals, there may be an over-expectation from the sector that cannot be met. Finally, an investigation of recent growth trends helps determine whether other areas of the health care sector, such as mental health or outpatient care, have seen increased spending growth in comparison to inpatient care.

21. To enable this more detailed analysis and assessment of the reported categories of inpatient hospital care expenditure additional data sources are used and adjustments applied in order to derive more comparable figures for somatic hospital care.

22. Finally, the appropriate use of international spatial deflators is discussed. Recent advances in the methodology to compile comparative price information for the health and hospital sectors can then reveal to what extent spending across the comparator countries is the result of price or volume effects. Some reflection is then given as to what is driving the differences in prices and volumes, with an initial discussion on efficiency and quality indicators in the hospital sector. 


\section{CHAPTER 2. UNRA VELLING AGGREGATE HEALTH SPENDING}

\section{Norway's level of wealth means that it is a high spender on health care}

23. The main observable non-demographic driver of health spending is income (De la Maisonneuve and Martins, 2013). Generally, with increasing levels of wealth, countries not only have more resources to spend on health, but also tend to allocate an increasing share of that wealth towards health. While higher income increases expectations on the quality and range of care, health care is at the same time an individual necessity (Lorenzoni et al, 2014 and 2015). However, while there is broad consensus that higher levels of income lead to more spending on health, the exact relationship between health expenditures and income (income elasticity) remains a contentious issue. Considering the varying degrees of development in economies and the availability and accessibility to public health care services, income elasticity can vary between high, middle and low-income countries.

24. In general, the wealth of the country, measured in terms of GDP, is a fundamental point of reference for all international comparisons of resources in the health sector. Even considering the relatively narrower band of income levels covered by OECD countries, there is a closer relationship between per capita GDP and health spending at the lower income range than appears at the upper income levels where there are a number of outliers (Figure 3). That said, per capita health spending in Norway would appear to be broadly in line with its level of wealth.

Figure 3. Per capita health spending and GDP in OECD countries, 2015

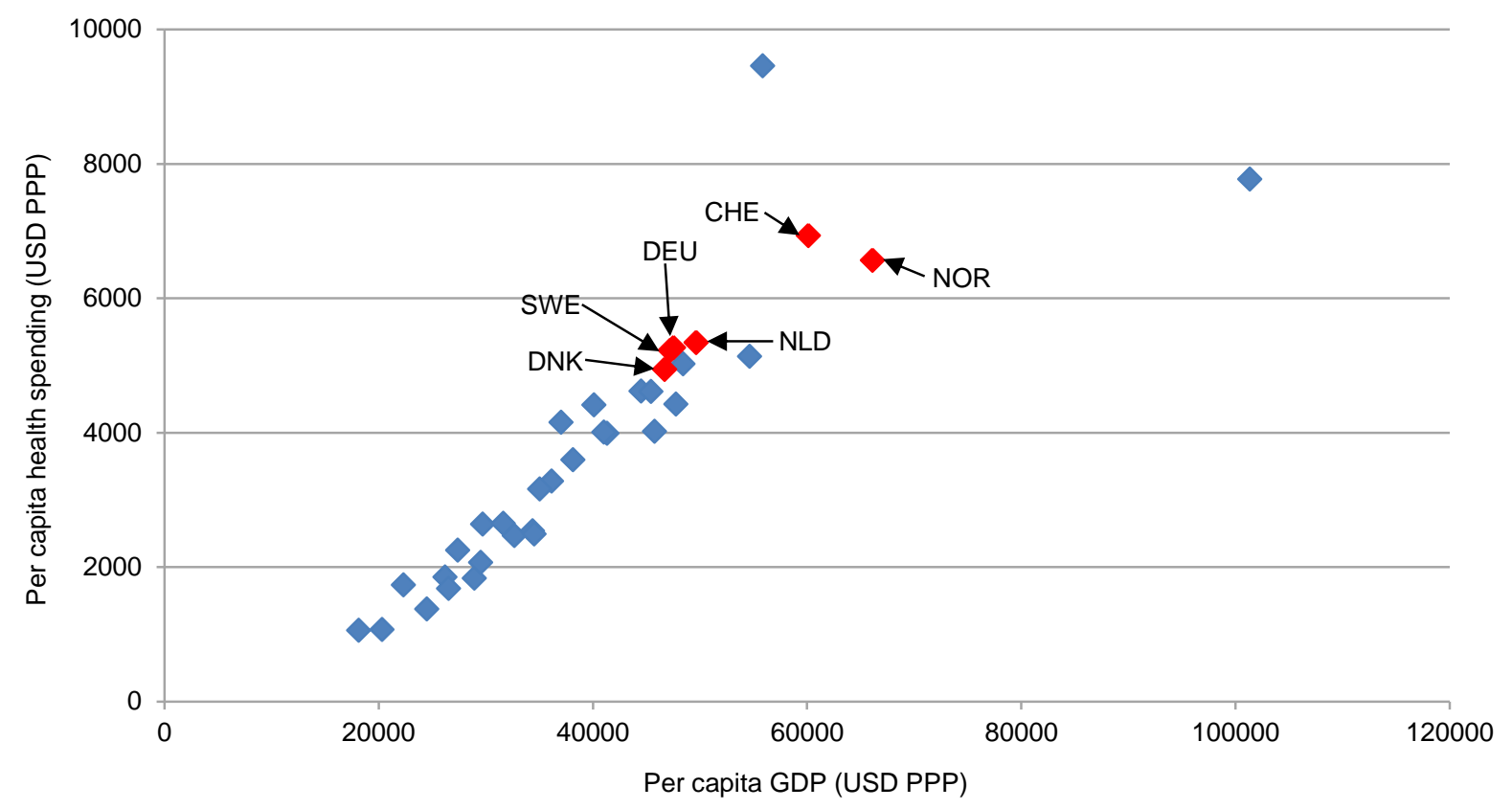

Data adjusted for differences in economy-wide price levels.

Source: OECD Health Statistics 2016. 
25. However, income levels together with demographic effects (that is, health costs increase with $\mathrm{age}^{3}$ ) only help explain some of the observed differences in health expenditure. Countries with similar levels of income exhibit different levels of health spending. Therefore, other factors such as technological progress, relative prices, institutional characteristics and health policies are put forward to explain the remaining difference or residual (De la Maisonneuve and Martins, 2013).

\section{Health as a share of GDP in Norway is lower than other countries due to its oil and gas production}

26. As explained, Norwegian per capita health spending is among the highest in the OECD. Among the group of six high-income comparator OECD countries, only Switzerland reports higher per capita health spending. Norwegian health spending is about two-thirds higher than the OECD average when adjusted for differences in general price levels between countries (Figure 4).

Figure 4. Health spending per capita and as a share of GDP, 2015

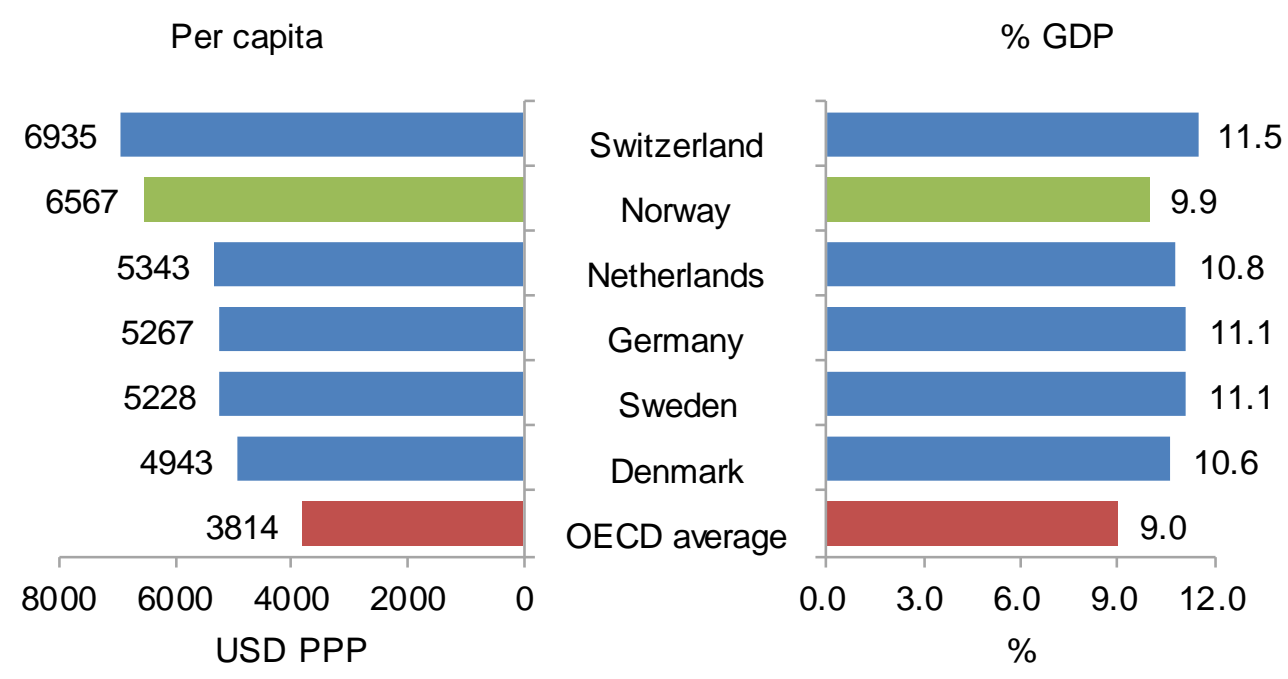

Data adjusted for differences in economy-wide price levels.

2015 data for Denmark is estimated by OECD.

Source: OECD Health Statistics 2016.

27. On the other hand, as a share of the economy, Norway allocates less to health than the other comparator countries. Typically, while the other comparator countries allocated an average of $11 \%$ of their GDP to health care in 2015, Norway allocated a lower share at $9.9 \%$. Note however, that this share has even increased significantly since 2013, when Norway's allocation to health was the same as the OECD average at $8.9 \%$.

28. To explain the disparity between these two measures, it is often pointed out that a large proportion of the Norwegian wealth is generated by oil and gas production, which is not available for public spending in the same way as other public revenue due to fiscal regulation. Removing such production (i.e. using only mainland GDP), would also remove the variability of price fluctuations in this major component of Norwegian GDP. Indeed, using this narrower measure of GDP as the denominator would result in health spending accounting for $11.9 \%$ of GDP in $2015^{4}$, a figure which might be considered

3. Ageing per se is not a main driver of health spending but rather the proximity to death for which the probability increases with age.

4. http://www.ssb.no/en/helsesat 
'in line' with the share of GDP in the comparator countries. However, a similar health spending to GDP ratio does not justify excluding from cross-country comparisons a sizeable part of the national economy that can potentially be allocated to health spending.

29. It does however highlight the need to understand more closely an indicator such as health spending as a share of GDP, which can depend on changes in both health spending and in the economy as a whole. Norway is a case in point, whereby the halving of the oil price between 2013 and 2015 contributed to a fall in export revenue and a decrease in the denominator GDP at current prices while health spending steadily increased in line with recent years (Figure 5). As a result of these changes in the size of GDP, health spending as a share of GDP jumped from $8.9 \%$ in 2013 to $9.9 \%$ in $2015^{5}$, bringing it much closer to the average of the other comparator countries.

Figure 5. Current health spending and GDP, Norway 2010-2015

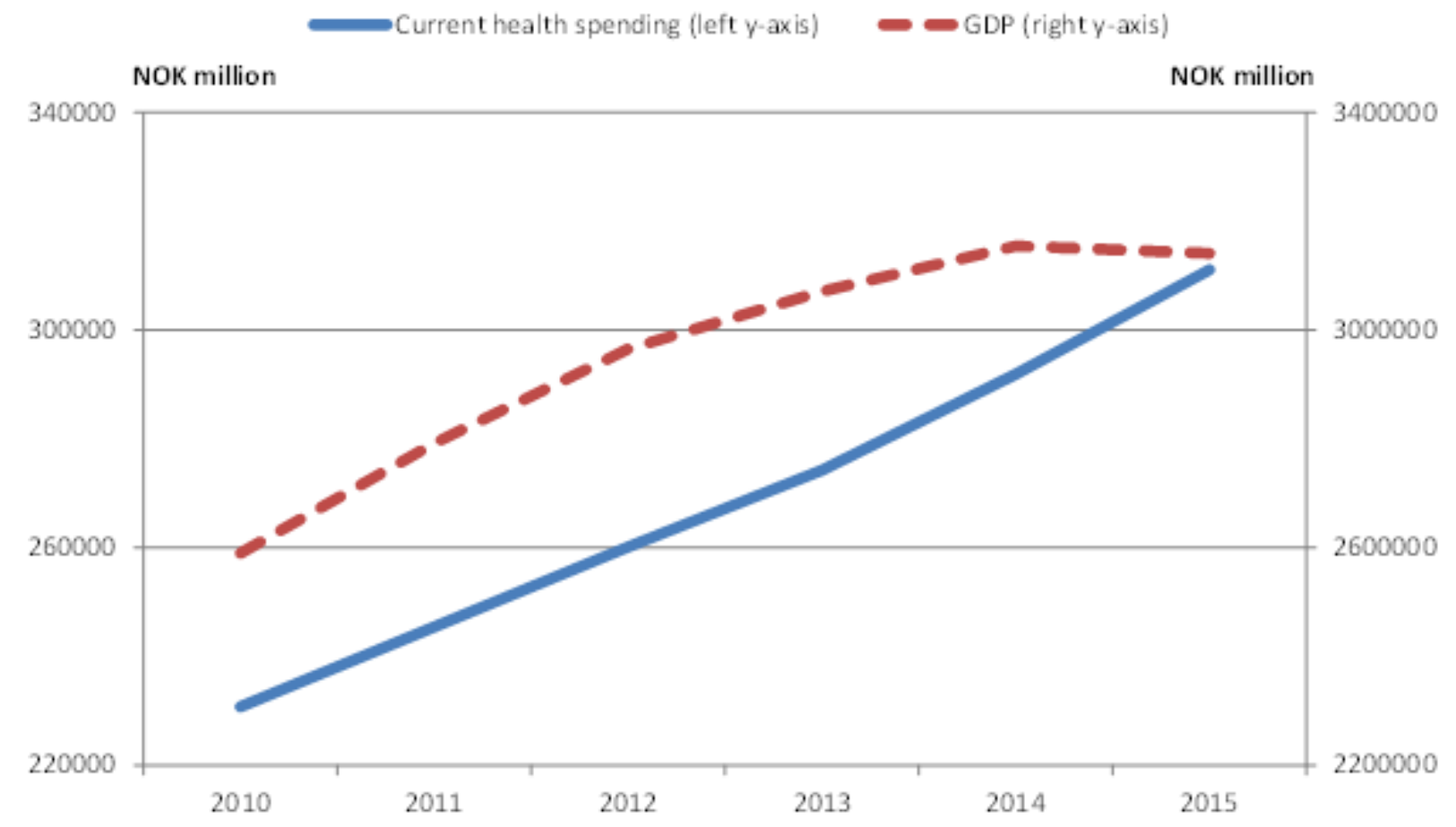

Source: Statistics Norway.

\section{Norway allocates a similar share of government spending to health as its neighbours}

30. The comparator countries in this report were selected for their comparable level of wealth and for representing both national health systems predominantly funded through general and/or local taxation, and those with funding based primarily on compulsory health insurance. While there are large differences in cost-sharing rules between the countries included in this report, there are relatively small differences in the shares of public and private spending, especially among the Scandinavian countries. Norway, in common with the other countries in this report, relies heavily on public resources to fund the health sector, i.e. differences in private spending do not explain much of the variation in health spending. Only Switzerland stands out with a relatively large share of out-of-pocket payments (OOP) (Table 1).

5. https://www.ssb.no/en/nasjonalregnskap-og-konjunkturer/statistikker/helsesat 
Table 1. GDP per capita and health spending, 2015

\begin{tabular}{|l|c|c|c|c|c|}
\hline & \multirow{2}{*}{$\begin{array}{c}\text { GDP/capita } \\
\text { USD PPP }\end{array}$} & \multicolumn{2}{|c|}{ Current health expenditure (CHE) } & \multicolumn{2}{c|}{ Health spending by type of financing } \\
\cline { 3 - 6 } & Per capita, USD PPP & $\%$ GDP & Public $^{\dagger}, \%$ CHE & OOP, \% CHE \\
\hline Denmark & 46693 & 4943 & 10.6 & 84.2 & $13.8^{*}$ \\
\hline Germany & 47520 & 5267 & 11.1 & 85.0 & 12.6 \\
\hline Netherlands & 49636 & 5343 & 10.8 & 80.7 & 12.2 \\
\hline Norway & $\mathbf{6 6 1 0 3}$ & $\mathbf{6 5 6 7}$ & $\mathbf{9 . 9}$ & $\mathbf{8 5 . 2}$ & $\mathbf{1 4 . 4}$ \\
\hline Sweden & 47224 & 5228 & 11.1 & 83.7 & 15.2 \\
\hline Switzerland & 60113 & 6935 & 11.5 & 67.9 & 25.1 \\
\hline OECD35 & $\mathbf{4 0 4 7 6}$ & $\mathbf{3 8 1 4}$ & $\mathbf{9 . 0}$ & $\mathbf{7 2 . 9}$ & $\mathbf{2 0 . 2 ^ { * }}$ \\
\hline
\end{tabular}

Data adjusted for differences in economy-wide price levels. *Refers to $2014 .{ }^{\dagger}$ Covers government and compulsory contributory financing schemes.

Source: OECD Health Statistics 2016.

31. Instead, an examination of aspects of public financing can help shed some light on the overall levels of health spending in Norway and by consequence the observed differences between per capita spending and share of GDP. The following section examines the share of GDP accounted for by public spending on health in terms of the two factors; first, the overall size of general government spending (as a share of the economy), and second, the proportion of government spending that is allocated to health. By separating the size of the government sector from how much of those public resources are devoted to health, the contribution to the relatively low levels of (public) health spending as a share of GDP of each can be better understood.

32. All countries in this report are high-income, although Norway has the most resources at its disposal per inhabitant. A fundamental factor in how much is spent on health in a system funded primarily out of public resources is to see the extent of government spending as a share of GDP. In this respect, Norway has a lower level than its neighbouring Nordic countries (Table 2). However, it is important to note that this share is not solely an explicit choice of public policy, but affected by many factors such as economic structure and the country's ability to raise and spend resources publicly, which goes beyond the scope of this report. In the case of Norway with its large revenue coming from the oil sector, the concept of fiscal space is difficult as it contains more complex considerations than for the other countries, as discussed above. In fact, the share of public spending to GDP has increased considerably over recent years $(44.0 \%$ to $48.8 \%$ between 2013 and 2015), due to the falling oil prices as discussed above.

33. However the second factor, the share of government spending devoted to health, shows that Norway compares closely with its Nordic neighbours in this indicator of public priorities, reporting $17.4 \%$ of general government expenditure spent on health. This is relatively less than the continental European countries, Germany, the Netherlands and Switzerland, although an important note is the difference in accounting for the spending of compulsory private schemes under general government expenditure in these two countries. 
Table 2. Size of GDP and public resources spent on health, 2015

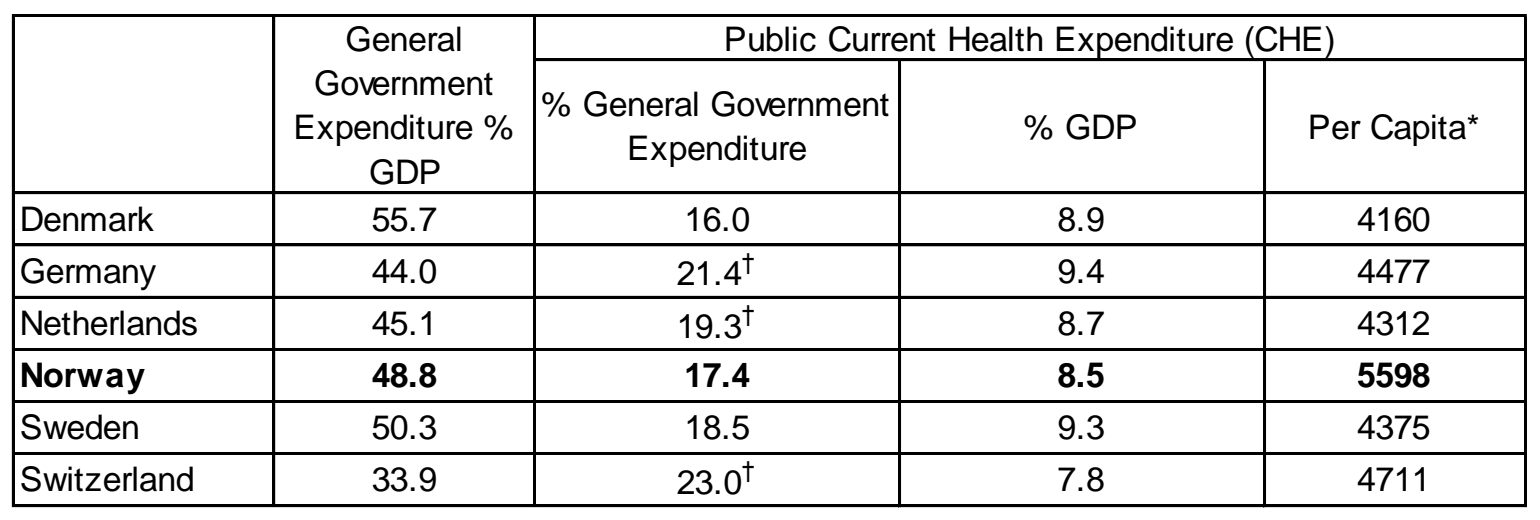

${ }^{*}$ Data adjusted for differences in economy-wide price levels. ${ }^{\dagger}$ Includes spending by compulsory private contributory schemes.

Source: OECD Health Statistics 2016; OECD National Accounts 2016.

34. In summary, Norway is a high spender on health in absolute terms due to its superior level of societal resources, i.e. the absolute amount of resources available in Norway contributes to the high levels of spending per capita. Norway also prioritises the health care sector, relative to other public services, on a par with its neighbouring countries, despite a relatively modest public sector. To the extent that GDP is dependent on oil revenues, the public sector as a share of GDP will increase as oil revenues decrease. In turn, the health spending ratio to GDP will increase as long as its relative priority is kept constant.

35. The disparity between high per capita spending and a low share of GDP is, of course, not restricted to the health care sector in Norway. A similar picture emerges if other sectors of the economy (e.g. social protection or education) are measured by the same two indicators. Of the same six countries, Norway's per capita spending on education, for example, was second again to Switzerland in 2013, but spending on education as a share of GDP was relatively low.

\section{Comparing health spending by type of care provides a better insight}

36. Moving from an overall measure of health spending to a more detailed analysis, there are significant country differences in how resources are distributed across different functions of health services. As such, the boundaries of health and health spending become important.

37. The System of Health Accounts ${ }^{6}$ (OECD, Eurostat and WHO, 2011) defines the boundaries of the health care system. Current health expenditure comprises personal health care (curative care, rehabilitative care, long-term care, ancillary services and medical goods) and collective services (prevention and public health services as well as health administration). Curative, rehabilitative and long-term care can also be classified by mode of production (inpatient, day care, outpatient and home care). Concerning long-term care, only the health aspect should be reported as health expenditure, although it is difficult in certain countries to separate out clearly the health and social aspects of long-term care. Figure 6 and Table 3 show the breakdown of spending by function of care across OECD countries.

6. The System of Health Accounts framework is organised around a tri-axial system for measuring current health expenditure. This tri-axial system is represented by classifications of the functions of health care (HC), health care provision (HP) and health care financing schemes (HF). Current health expenditure can therefore be broken down by function, by provider, by financing scheme or by combinations of the three dimensions. 
Figure 6. Current health expenditure by function of care, OECD countries, 2014 (or nearest year)

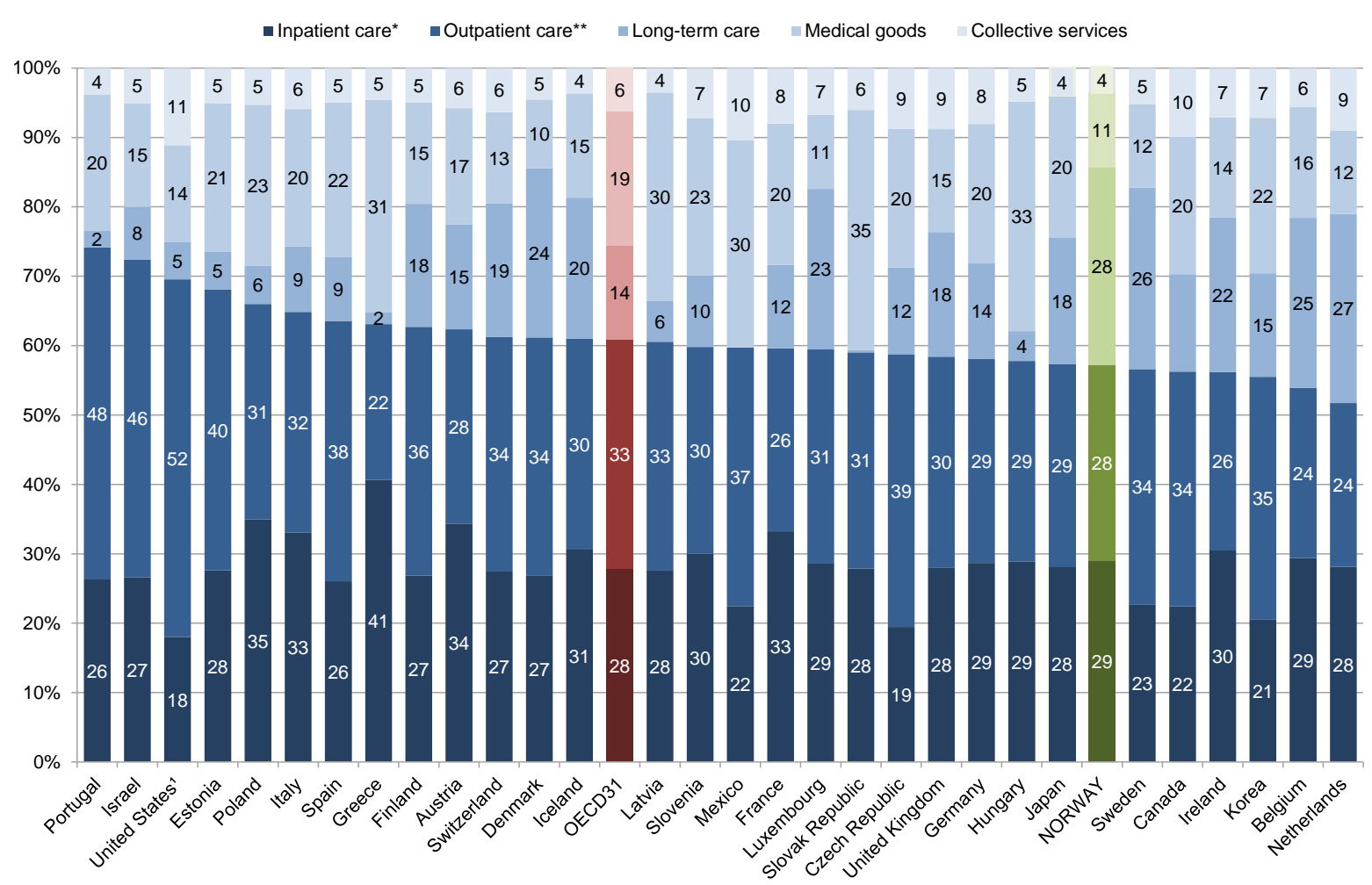

Countries are ranked by curative-rehabilitative care as a share of current expenditure on health.

*Refers to curative-rehabilitative care in inpatient and day care settings. ${ }^{*}$ Includes home-care and ancillary services.

1. Inpatient services provided by independent billing physicians are included in outpatient care for the United States.

Source: OECD Health Statistics 2016.

38. The functional approach to health care expenditure measurement removes some of the organisational and institutional aspects from cross-country comparisons; for example, the differing roles of hospitals between countries in the provision of care. That said, a functional category such as inpatient care can cover a large proportion of services across different providers and a closer investigation may be needed to provide a more refined measure (see Chapter 3). Moreover, each component of health spending is affected by the relative shares of the other components. For example, any differences in long-term care spending obviously have an impact on the relative shares of inpatient and outpatient care and vice versa.

39. Denmark is probably one of the countries with the most similar organisation of the health care system as Norway, and a particular focus on these two countries is useful when it comes to analysing spending on specific health care components. Organisation of drug dispensing in both countries means that spending on retail pharmaceuticals (included under "medical goods") is relatively low in both countries, while total spending on inpatient and day care accounts for a slightly higher share in Norway (see Chapter 3 ). The organisation and accounting of independent ancillary services (such as diagnostic imaging and laboratory tests) and home-care services accounts for the large difference in the share of health spending on outpatient services. 
DELSA/HEA/WD/HWP(2017)1

Table 3. Health spending on selected functions of health care, 2014

\begin{tabular}{|c|c|c|c|c|c|c|c|c|}
\hline & \multicolumn{2}{|c|}{ Inpatient care* } & \multicolumn{2}{|c|}{ Outpatient care } & \multicolumn{2}{|c|}{ Long-term care } & \multicolumn{2}{|c|}{ Pharmaceuticals ** } \\
\hline & $\begin{array}{l}\text { Per capita, } \\
\text { USD PPP }\end{array}$ & $\% \mathrm{CHE}$ & $\begin{array}{l}\text { Per capita, } \\
\text { USD PPP }\end{array}$ & $\% \mathrm{CHE}$ & $\begin{array}{l}\text { Per capita, } \\
\text { USD PPP }\end{array}$ & $\% \mathrm{CHE}$ & $\begin{array}{l}\text { Per capita, } \\
\text { USD PPP }\end{array}$ & $\% \mathrm{CHE}$ \\
\hline Denmark & 1302 & 26.8 & 1448 & 29.8 & 1183 & 24.4 & 325 & 6.7 \\
\hline Germany & 1468 & 28.7 & 1155 & 22.6 & 708 & 13.8 & 741 & 14.5 \\
\hline Netherlands & 1484 & 28.1 & 1116 & 21.2 & 1437 & 27.2 & 401 & 7.6 \\
\hline Norway & 1760 & 28.9 & 1251 & 20.6 & 1724 & 28.4 & 457 & 7.5 \\
\hline Sweden & 1148 & 22.7 & 1504 & 29.7 & 1326 & 26.2 & 489 & 9.6 \\
\hline Switzerland & 1863 & 27.5 & 2063 & 30.4 & 1306 & 19.2 & 730 & 10.8 \\
\hline
\end{tabular}

Per capita figures adjusted for differences in economy-wide price levels. ${ }^{\star}$ Refers to curative/rehabilitative care in inpatient and day care settings. ${ }^{\star *}$ Includes medical non-durables.

Source: OECD Health Statistics 2016.

\section{Spending on long-term care is a key component of health spending in high-income countries}

40. Long-term care (LTC) expenditure can have a significant effect on the overall level of countries' health expenditure. Countries such as Norway, the Netherlands, Sweden and Denmark all have high levels of social protection with well-established formal arrangements in place for the care of the elderly and disabled, resulting in a high proportion of LTC expenditure in overall health spending; typically a quarter or more of health spending is allocated to long-term care services in these countries. Norway was the OECD country that spent more per capita on long-term care services and had the largest share of overall health spending allocated to long-term care in 2014. This contrasts with other European countries (e.g. Spain and Portugal) where more informal (often family-based) arrangements prevail and, as a result, the share of long-term care spending in total health spending is significantly less. On average OECD countries allocate around half the share of health spending to long-term care (14\%) compared to Norway; and a number of OECD countries report less than 5\% of health spending paying for LTC services.

41. The main driver of LTC spending, in addition to income, is the number of dependents requiring care and the need for public formal care (De la Maisonneuve et al, 2013). High labour participation rates are often taken as a proxy for the need for public formal care - a characteristic that is typically shared among the comparator countries: Figure 7 shows that the number of formal care workers (in both institutions and providing home care) is much higher in countries such as Sweden, the Netherlands and Denmark compared to countries in southern and central Europe ${ }^{7}$.

42. The extent to which the amount of spending on LTC is a determining factor in overall health spending also depends on the correct identification and allocation of such expenditure. Significant progress has been made in recent years to better define and measure long-term care within the health accounts framework to arrive at comparable measures of spending; in particular allocating LTC expenditure in an internationally consistent way between health and social care spending ${ }^{8}$. While some difficulties remain for a number of countries, including, for example, the identification of private LTC spending, the degree of harmonisation among the six comparator countries is considered close ${ }^{9}$.

7. Comparable figures for Norway are unavailable.

8. SHA 2011 distinguishes both health and social components of LTC spending. The health component which roughly equates to the provision of medical and personal care services to long-term dependant persons is included under health spending.

9. Until recently Sweden was not able to report comparable estimates of LTC according to SHA definitions leading to an underestimate compared with Norway. From 2011 the data has included LTC with a breakdown in Inpatient LTC, Day LTC and Home-based LTC. This also makes the aggregate health expenditure data more comparable to Norway. 
Figure 7. Long-term care workers per 100 people aged 65 and over, 2013 (or nearest year)

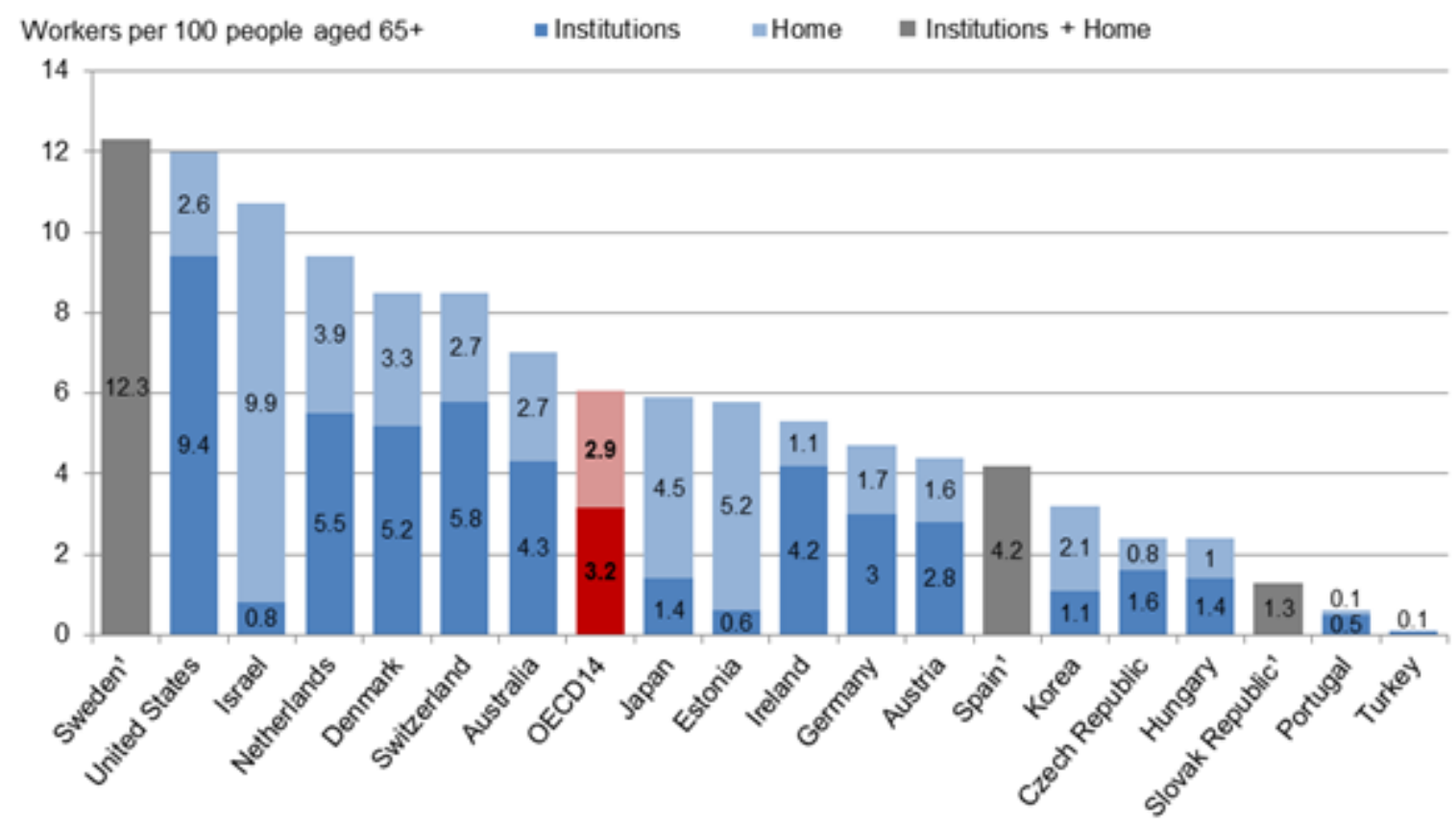

1. In Sweden, Spain and the Slovak Republic, it is not possible to distinguish LTC workers in institutions and at home.

Source: OECD Health at a Glance 2015.

43. Figure 8 presents per capita health spending for OECD countries alongside the share of health spending allocated to long-term care services. It is noticeable that generally those OECD countries with higher spending on health also generally have the highest share allocated to LTC. There are a couple of notable outliers excluded from the chart - namely United States and Australia. In the latter case, a much narrower definition of LTC is applied in the compilation of health spending which means that both overall health spending and the share allocated to LTC is underestimated. At the other end of the scale, countries such as Israel and the Slovak Republic have difficulty in identifying spending on LTC. However, the share allocated to LTC in these countries would be expected to be roughly in line with that of countries with a similar level of health spending - that is, between $5 \%$ and $10 \%$ of current expenditure on health. 
Figure 8. Per capita health spending and LTC share, OECD countries, 2014

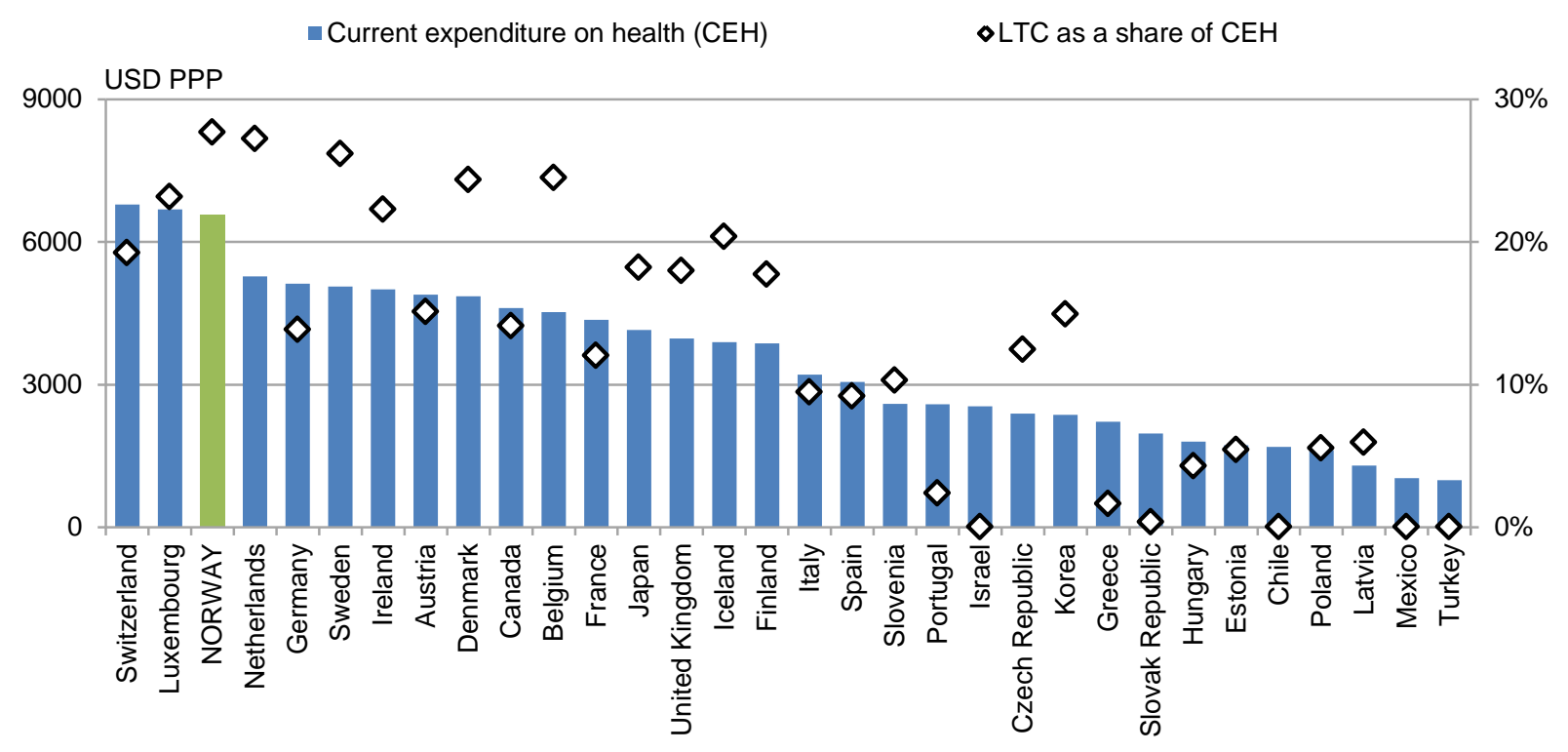

Data adjusted for differences in economy-wide price levels.

Source: OECD Health Statistics 2016.

44. In summary, among OECD countries and more specifically among the comparator countries included in this study, the share of LTC spending is strongly correlated to the overall level of health spending, and in turn, overall income levels. Interestingly, those countries with relatively high private sector payments in the LTC sector - Switzerland and Germany - tend to see a lower share of health spending allocated to LTC, compared with the other four countries where public coverage is much higher (i.e. where public financing accounts for more than $90 \%$ of reported LTC spending).

\section{Most countries have seen health spending fall as a result of the economic crisis}

45. The global economic crisis which began in 2008 had a dramatic effect on health spending across OECD countries, and more particularly in Europe. Health expenditure figures showed that spending slowed markedly or fell across many OECD countries after years of continuous growth. As a result, close to zero growth in health expenditure was recorded on average in 2010 (Morgan and Astolfi, 2013 and 2014). Many European countries saw further reductions in health spending in the following years, with further decreases in Greece, Italy and Portugal in 2013. Most countries in the European Union reported real per capita health spending below the levels of 2009.

46. Among the six comparator countries, all but Switzerland saw a fall in the annual average growth of health spending compared with the period before the crisis - Denmark saw an overall contraction in health spending (Figure 9). It is noticeable that, across all OECD countries, those countries with predominantly tax-funded health systems saw lower growth in health spending since budgetary instruments were more easily available to be used to constrain public spending, in contrast to the more restricted manoeuvrability of social-insurance based financing. 
Figure 9. Annual average growth in per capita health spending, real terms ${ }^{\star}, 2005-2014$ (or nearest years)

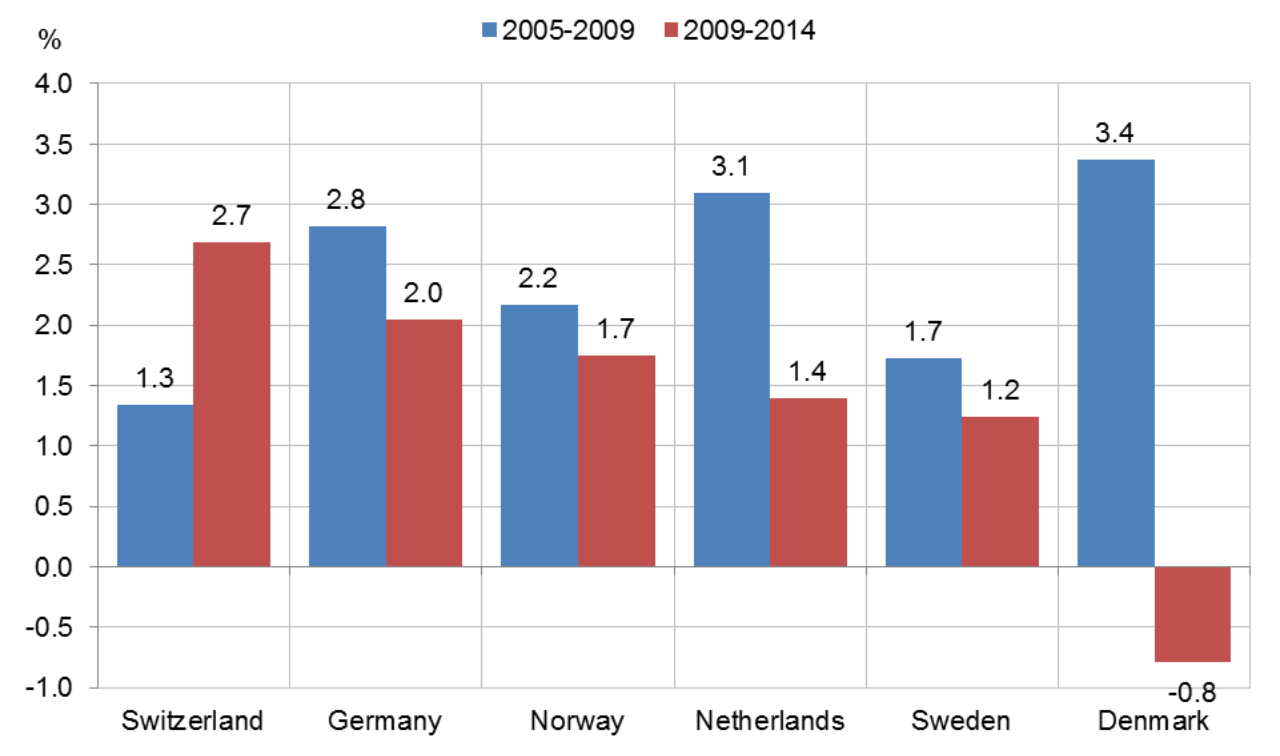

*Nominal health spending is deflated using a GDP deflator. A health-sector specific deflator is available from Statistics Norway to deflate Norwegian health spending. The use of the health-specific deflator would give lower growth overall with $+1.3 \%$ for $2005-09$ and $+0.2 \%$ for $2009-14$.

Source: OECD Health Statistics 2016.

47. Decomposing health spending into the main spending categories of inpatient care, outpatient care, long-term care and pharmaceuticals reveals different patterns both between the components and the countries (Table 4) ${ }^{10}$. Pharmaceutical spending growth has slowed in many countries since the mid-2000s, exacerbated in some countries by the economic crisis. The slowdown is also due to ongoing price-cutting measures and the result of the loss of patents for some high-cost high-volume drugs (Belloni et al, 2016). The trends are made more complex with the different distribution and dispensing patterns in countries ${ }^{11}$.

48. Generally, a greater drop in the inpatient sector compared with outpatient spending can be observed in most of the countries, as a shift to less resource intensive outpatient services was sought while front-line primary care services were "ring-fenced" in any measures taken. A more detailed discussion of trends in the somatic hospital sector in Norway is part of Chapter 3, while trends towards reducing average length of stay (ALOS) and the use of day surgery is covered in Chapter 4.

10. For international comparisons of growth rates, economy-wide price deflators are traditionally used due to their widespread availability. However, by their nature, they do not necessarily reflect well the price changes in the health sector as a whole or in the various components, e.g. pharmaceuticals. As such, the results can differ significantly from national sector-specific measures of volume changes.

11. For example, a much higher proportion of total pharmaceutical expenditure relates to hospital pharmaceuticals in Denmark compared with Germany (Hostenkamp, 2011) 
Table 4. Annual average growth in per capita health spending for selected functions of health care, real terms, 2005-2014 (or nearest years)

\begin{tabular}{|c|c|c|c|c|}
\hline & Inpatient care* & Outpatient care & Long-term care & Pharmaceuticals ${ }^{* *}$ \\
\hline \multicolumn{5}{|l|}{ Denmark } \\
\hline $2005-2009$ & $4.5 \%$ & $3.1 \%$ & $3.7 \%$ & $0.3 \%$ \\
\hline $2009-2013$ & $-2.1 \%$ & $1.5 \%$ & $-1.3 \%$ & $-5.3 \%$ \\
\hline \multicolumn{5}{|l|}{ Germany } \\
\hline $2005-2009$ & $2.5 \%$ & $3.0 \%$ & $2.7 \%$ & $2.5 \%$ \\
\hline 2009-2014 & $2.4 \%$ & $1.9 \%$ & $2.8 \%$ & $1.0 \%$ \\
\hline \multicolumn{5}{|l|}{ Netherlands } \\
\hline 2005-2009 & $3.8 \%$ & $4.6 \%$ & $2.9 \%$ & $0.7 \%$ \\
\hline 2009-2014 & $0.6 \%$ & $2.3 \%$ & $3.5 \%$ & $-4.0 \%$ \\
\hline \multicolumn{5}{|l|}{ Norway } \\
\hline 2005-2009 & $2.5 \%$ & $1.4 \%$ & $4.7 \%$ & $-3.8 \%$ \\
\hline 2009-2014 & $0.4 \%$ & $3.4 \%$ & $1.6 \%$ & $1.5 \%$ \\
\hline \multicolumn{5}{|l|}{ Sweden } \\
\hline 2005-2009 & $1.4 \%$ & $2.4 \%$ & $0.7 \%$ & $0.9 \%$ \\
\hline 2009-2014 & $0.9 \%$ & $2.2 \%$ & $1.2 \%$ & $-0.7 \%$ \\
\hline \multicolumn{5}{|l|}{ Switzerland } \\
\hline 2005-2009 & $1.3 \%$ & $1.6 \%$ & $1.5 \%$ & $0.2 \%$ \\
\hline $2010-2014$ & $2.4 \%$ & $4.1 \%$ & $2.7 \%$ & $1.3 \%$ \\
\hline
\end{tabular}

${ }^{*}$ Refers to curative/rehabilitative care inpatient and day care settings. ${ }^{* *}$ Includes medical non-durables.

Source: OECD Health Statistics 2016. 


\section{CHAPTER 3. A BETTER MEASURE OF HOSPITAL INPATIENT SPENDING}

49. Levels and trends of overall health spending are to a large extent driven by developments in the hospital inpatient sector as inpatient care accounts for close to one-third of total current expenditure in Norway and the comparator countries. This chapter derives a more comparable measure of hospital inpatient spending to give a clearer picture of cross-country differences in both the spending levels and the relative importance of hospital inpatient spending vis-à-vis other health spending. The chapter concludes with a comparison of trends in somatic care and mental health spending in the hospital inpatient sector.

\section{International estimates of inpatient care are affected by the different organisation of mental health among countries}

50. Health expenditure data compiled according to the definitions of the System of Health Accounts (SHA) framework contain information on how much is spent on inpatient curative and rehabilitative care (SHA code: HC.1.1+HC.2.1) provided in hospitals (SHA code: HP.1). While hospital inpatient spending as reported in the countries' SHA data is generally comparable, a further analysis points to some important cross-country differences affecting international comparability.

51. Firstly, whereas hospital inpatient spending does indeed refer to medical treatments for hospital inpatients in Norway, Germany and Sweden, the data for Switzerland, Denmark and the Netherlands also include spending on day cases of curative and rehabilitative care. In contrast to hospital inpatient care, where patients are formally admitted into a hospital for treatment and are expected to stay overnight, day care comprises planned medical and paramedical services delivered to patients who have been formally admitted but are expected to be discharged on the same day (OECD, Eurostat, WHO, 2011, p. 79). As Norway, Germany and Sweden provide separate estimates on day curative and rehabilitative care (SHA code: HC.2.1+HC.2.2) through their health accounts, for the sake of international comparability, hospital day care spending was added to hospital inpatient spending for these countries. This adjustment increases hospital inpatient spending in Norway, Germany and Switzerland by 5.6\%, 1.6\% and 9.1\%, respectively (Figure 10).

52. A second important difference affecting the international comparability of hospital inpatient spending concerns the treatment of ancillary services (i.e. laboratory and imaging services) consumed as part of hospital inpatient care. According to SHA definitions, ancillary services that a patient consumes in a hospital during an inpatient stay (e.g. a blood test or an X-ray for a patient admitted for surgery), should be considered as part of hospital inpatient care as such services are an integral part of the inpatient treatment package. On the other hand, ancillary services that are consumed during an independent contact with the health system, even if provided in a hospital, should be recorded under a different functional category (SHA code: HC.4), that is separate from inpatient care (e.g. when a patient was referred by her GP to do a blood test or an X-ray and visits a hospital solely for that purpose).

53. Both Norway and Denmark are unable to distinguish between the two types and report ancillary services for hospital inpatients under this separate category rather than including it with inpatient care. In contrast, Switzerland, Germany, the Netherlands and Sweden are able to distinguish between those ancillary services provided in hospitals to inpatients and those provided to patients during an independent contact with the health system. This results in an underestimation of hospital inpatient spending in Norway and Denmark to the extent that expenditure on ancillary services for hospital inpatients is excluded.

54. To adjust for this underestimation, the share of ancillary services provided to hospital inpatients in Norway and Denmark is approximated using the overall health spending structure of other OECD countries. Based on information from OECD Health Statistics 2015, OECD countries (excluding Norway 
and Denmark) spent on average $2.7 \%$ of current health expenditure on laboratory and imaging services, the respective shares for Norway and Denmark are $4.6 \%$ and 3.7\%. However, whereas the OECD average refers only to ancillary services provided to patients during an independent contact with the health system, the values for Norway and Denmark also include ancillary services provided to hospital inpatients. Assuming that the 1.9 percentage point surplus in Norway compared to the OECD average refers to ancillary services for hospital inpatients, approximately $48 \%$ of spending on laboratory and imaging services in Norwegian hospitals stem from inpatient treatments. The same exercise for Denmark implies that about $31 \%$ of expenditure on hospital ancillary services relate to inpatient treatments rather than independent visits. These adjustments increase hospital inpatient spending in Norway and Denmark by $7.3 \%$ and $3.6 \%$, respectively (Figure 10 ).

Figure 10. From unadjusted hospital inpatient care to somatic hospital inpatient care

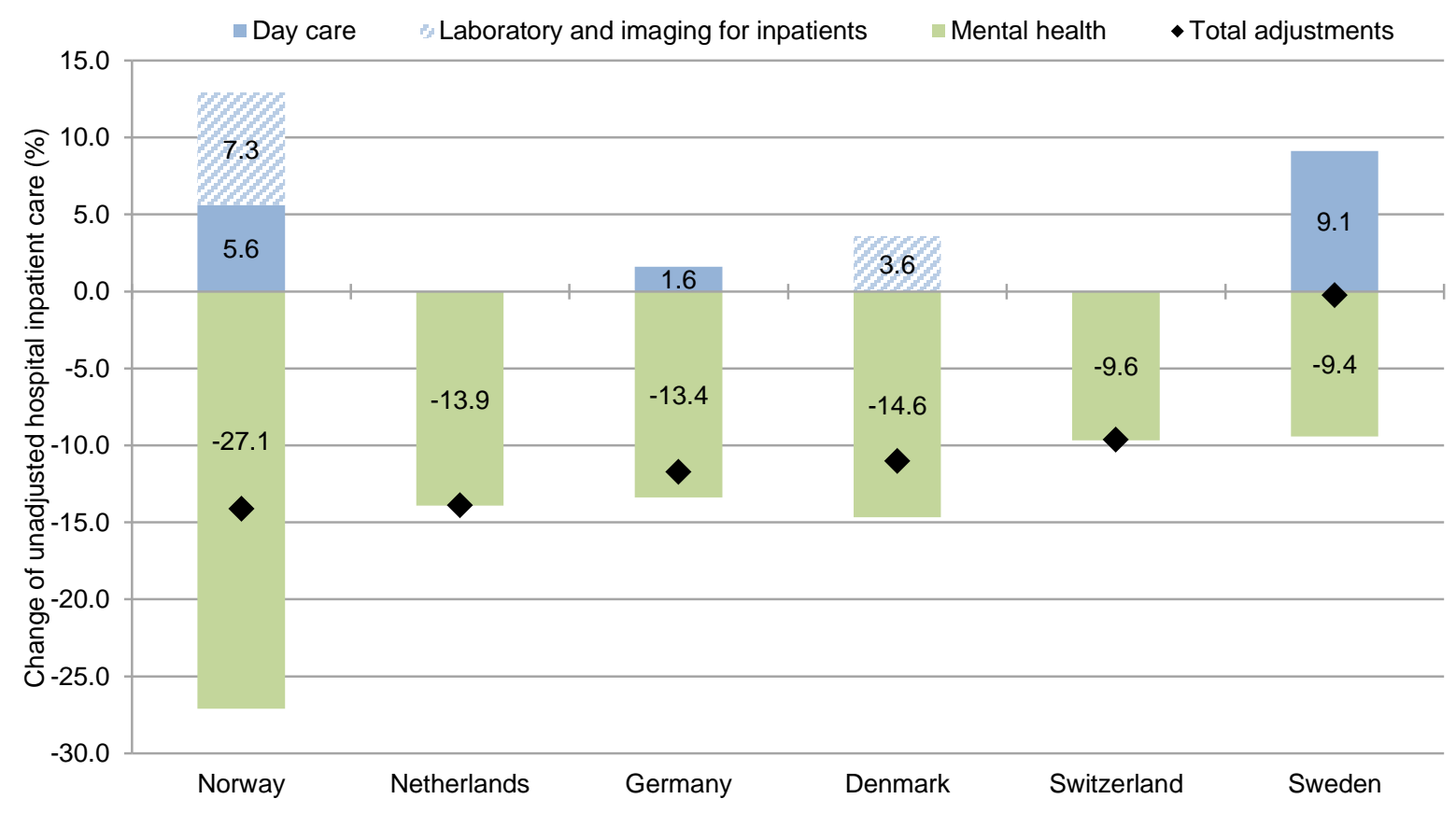

Source: OECD Health Statistics 2016; OECD estimates.

55. Hospital inpatient spending, as reported in the SHA data, can cover somatic care as well as care related to mental health and substance abuse. As a result, variations in hospital inpatient spending do reflect to some degree differences in the organisation of care for mental health and substance abuse patients and the settings in which such services are provided. Furthermore, there remain some grey areas between mental health and substance abuse and long-term care. Consequently, for a cross-country comparison of hospital inpatient spending, we are focussing on somatic care which is assumed to be more homogeneous across countries in terms of both the kinds of health care services provided and the institutional setting in which care is delivered.

56. Norway as well as the comparator countries Switzerland, Denmark and the Netherlands report expenditure on inpatient care (including day cases) provided in mental health hospitals (SHA code: HP.1.2). In Norway and Denmark, all spending on mental health and substance abuse in hospitals is captured by this category, which can be subtracted from hospital inpatient spending to arrive at a measure capturing somatic care for hospital inpatients. Similarly, in Switzerland and the Netherlands the majority of spending on mental health care in hospitals is captured by the category HP.1.2, but smaller amounts of 
mental health spending are also included in spending on inpatient care (including day cases) in general hospitals (SHA code: HP.1.1) and specialised hospitals other than mental health hospitals (SHA code: HP.1.3). An estimate to exclude these spending components is made for both countries based on available Expenditure by Disease information ${ }^{12}$. Germany and Sweden do not report any spending for mental health hospitals in their SHA data. Expenditure by Disease information is available to make an estimate that allows the exclusion of mental health spending from hospital inpatient care.

57. Compared to the unadjusted figures taken from SHA data, the exclusion of mental health care in hospitals leads to significant decreases in hospital inpatient spending, albeit to varying degrees across countries (Figure 12). Mental health accounts for more than a quarter of (unadjusted) hospital inpatient spending in Norway, but only $13-15 \%$ in Denmark, the Netherlands and Germany and less than 10\% in Switzerland and Sweden.

58. The result of adjusting for statistical differences (reporting of day care and ancillary services) as well as excluding mental health care in hospitals is a more comparable measure of somatic hospital inpatient care. Somatic hospital inpatient spending in Norway is $14 \%$ lower than the unadjusted hospital inpatient spending figures as reported in the SHA data (Figure 12). Similarly, the adjustments lead to significantly lower somatic hospital inpatient spending in the Netherlands $(-14 \%)$, Germany $(-12 \%)$, Denmark (-11\%) and Switzerland (-10\%). In Sweden the net effect of the adjustments is close to zero. The derived measure of somatic hospital inpatient spending will be the basis for the following comparisons in this chapter (Figures, 11, 12,13) and in Chapter 4 (Figure 17).

\section{Norway spends more per capita on somatic care but a similar share of health spending as its neighbours}

59. Norway spends more on somatic hospital inpatient care per capita than most of the comparator countries (Figure 11). In 2013, per capita spending on somatic hospital inpatient care stood at USD 1338. Germany, Denmark and the Netherlands each had per capita spending of just below USD 1200 which amounts to around $85-90 \%$ of Norwegian spending, whereas Sweden spent only about three-quarters of the Norwegian level. Switzerland had the highest somatic hospital inpatient spending, with per capita spending about one-quarter higher than in Norway.

60. It should be noted that the measures of hospital inpatient spending presented in Figure 11 have been adjusted for differences in economy-wide price levels. The remaining variations in somatic hospital inpatient spending across countries reflect not only variations in the volume of hospital services, but also any variations in the prices of hospital services relative to the commonly used economy-wide prices. The question, therefore, remains whether relatively high per capita spending in Norway is owed to high comparative price levels in the hospital sector or to higher consumption of hospital services (or a mix of the two). This question will be addressed in Chapter 4.

12. Expenditure by Disease data for Switzerland (2011), the Netherlands (2011), Germany (2008) and Sweden (2012). See also: http://www.oecd.org/els/health-systems/estimating-expenditure-by-disease-age-and-gender.htm 
Figure 11. Per capita spending on (somatic) hospital inpatient care, 2013

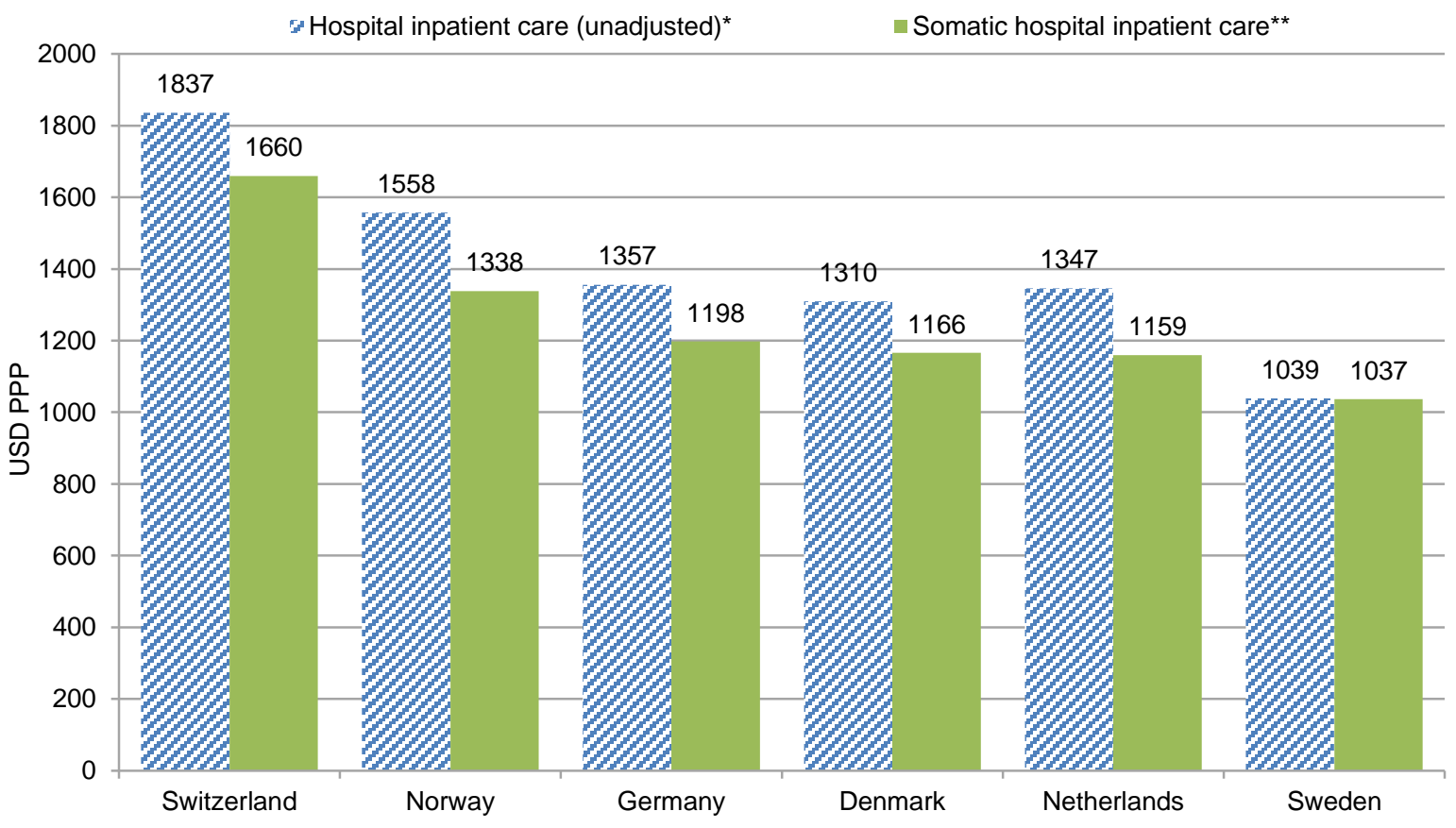

Data adjusted for differences in economy-wide price levels (USA=1). ${ }^{*}$ Refers to inpatient curative and rehabilitative care in hospitals as reported in SHA data. ${ }^{* *}$ Includes day cases of curative and rehabilitative care in hospitals and ancillary services for inpatients, excludes spending on mental health and substance abuse in hospitals.

Source: OECD Health Statistics 2016; OECD estimates.

61. Despite the relatively high level of per capita spending, Norway does not spend more on somatic hospital inpatient care relative to other individual health care services and goods than the other countries (Figure 12). In other words, the share of health spending devoted to the hospital inpatient sector is line with what is observed in the five comparator countries. Indeed, no substantial differences between the countries are observed, with the share of spending on individual health care services and goods going to somatic hospital inpatient care ranging from $30 \%$ in Sweden to $34.7 \%$ in Denmark. The $33.1 \%$ share for Norway corresponds roughly to the average across the six countries. 
Figure 12. Somatic hospital inpatient spending as a share of all spending on individual health care services and goods, 2013

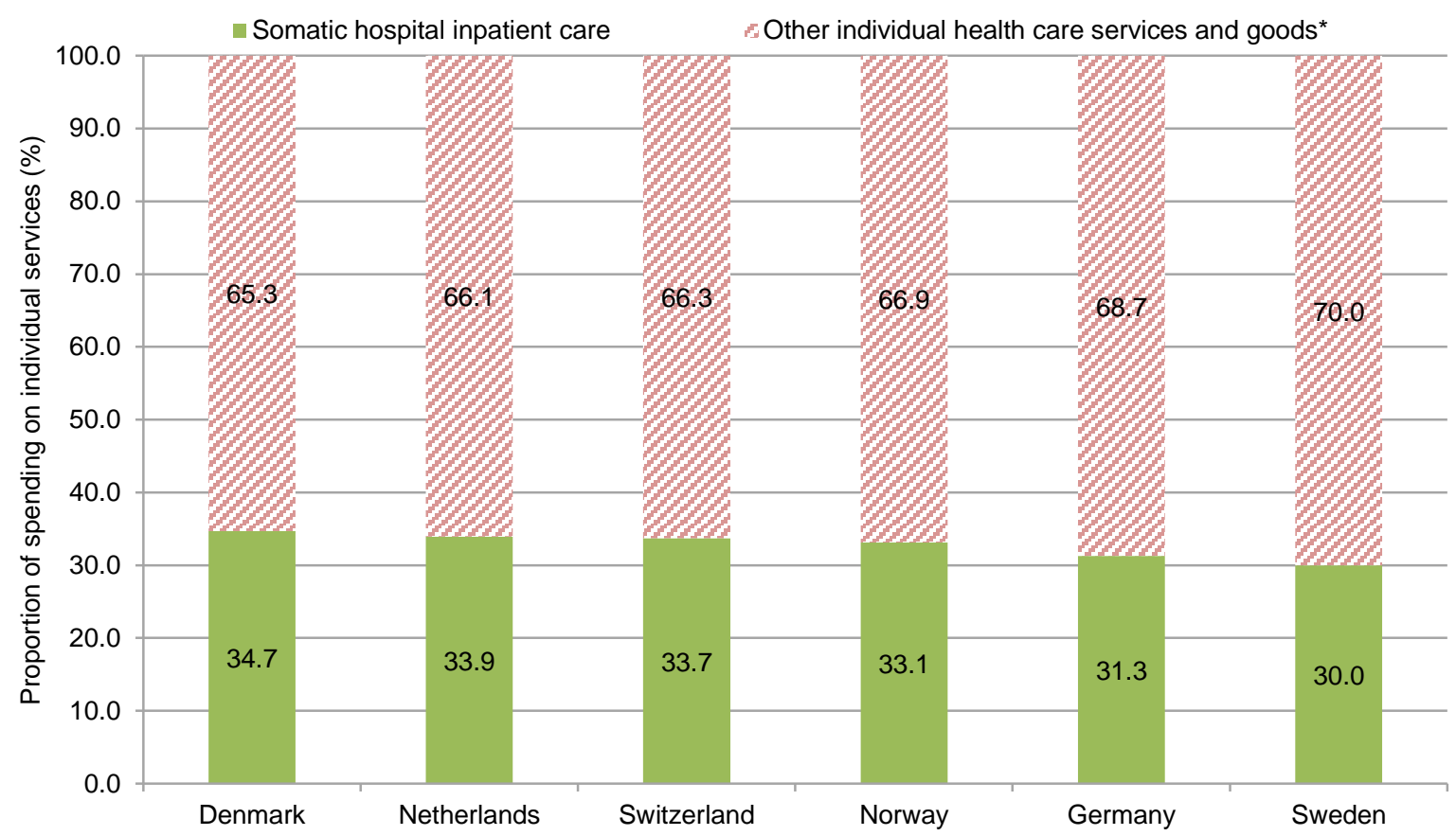

${ }^{*}$ Refers to current health expenditure excl. somatic hospital inpatient care, long-term care, prevention and administration.

Source: OECD Health Statistics 2016; OECD estimates.

62. In summary, a refined measure of hospital inpatient care focussing on somatic care shows that Norway spends more per capita on such services than the other comparator countries except Switzerland. However, relative to other health care goods and services, hospital inpatient spending in Norway seems to be broadly in line with the other countries, when compared with the spending on other individual health care services and goods.

\section{Spending on mental health/substance abuse continues to grow while volumes appear to have fallen}

63. In recent years, spending on inpatient somatic care and mental health/substance abuse care in hospitals in Norway would, based on health accounts data, appear to have developed quite differently (Figure 13). During the period between 2005 and 2009, spending on both types of care grew at very similar rates - equating to around $8 \%$ average annual growth year on year in nominal terms - whereas there has been a divergence of spending growth in the two sectors since then. While mental health/substance abuse spending continued to see similar rates of growth up to 2013, spending growth on somatic inpatient care reduced to around half the previous annual growth rate (4\% per annum), with spending growth between 2010 and 2011 notably flat. In 2004, the responsibility for all substance abuse treatment and rehabilitation services was transferred from the counties to the Regional Health Authorities and these services are now part of specialised care services. Since 2004 there has been an agreement to increase the capacity and quality of the services in substance abuse treatment.

64. However, the observed spending trends for both somatic and mental health/substance abuse care are to some degree affected by statistical changes. The relatively low growth of somatic inpatient care spending between 2010 and 2011 is partly driven by a statistical change regarding the treatment of hospital 
spending on $R \& D^{13}$. From 2011, spending on $R \& D$ in hospitals is classified as capital expenditure and only the consumption of this R\&D capital is included in somatic inpatient care spending. Prior to 2011 expenditure on R\&D in hospitals was in its entirety included under somatic inpatient care. As a result, from 2011 somatic inpatient care spending is somewhat lower than it would have been without this revision. Furthermore, information from the Norwegian DRG system is used to split somatic hospital spending into its inpatient, day care and outpatient components. Therefore, changes to the DRG system might affect the share of somatic hospital spending allocated to inpatient care. On the other hand, mental health spending between 2005-2010 does not include spending on substance abuse treatment in private hospitals, whereas such spending is included from 2011 onwards, thus leading to somewhat overstated growth in 2011.

Figure 13. Trends in hospital inpatient spending, nominal terms, 2005-2013

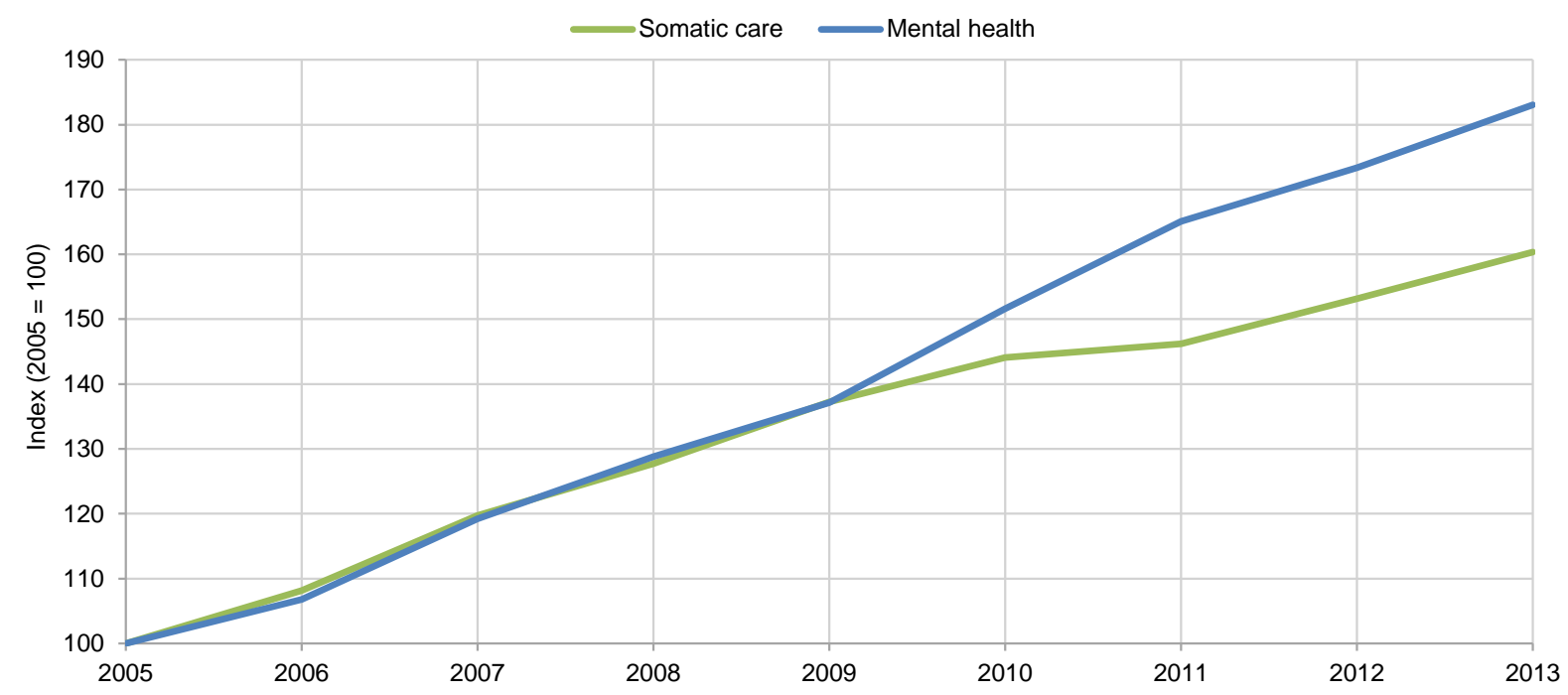

Note: Somatic care and mental health care exclude day care spending.

Source: OECD Health Statistics 2016; Statistics Norway.

65. In the inpatient mental health sector, data on bed-days are often used as a measure of volumes of services in order to construct an implicit price deflator. Treatments tend to be generally more homogeneous and less resource intensive (in terms of medical technology and interventions) than in the somatic care sector where accounting for case mix and resources, for example using DRG-based information, is required. Figure 14 shows that the number of psychiatric (mental health) bed-days has continually fallen over the period from 2005 to 2015 - by an average of $3.6 \%$ year on year. In contrast, and reflecting the 2004 agreement to increase capacity around the treatment of substance abuse, the volume of bed-days for drug treatment has, on average, increased since 2005: the number of bed-days for drug treatment as a share of total psychiatric and drug treatment bed-days increased from 25\% in 2005 to 35\% in 2015. However, due to the larger drop in psychiatric bed-days, the overall implicit "cost per bed-day" index has grown at more than $10 \%$ year on year.

13. This change is related to the implementation of the System of National Accounts 2008 (SNA 2008) which treats expenditure on R\&D as capital formation ("investment"). Earlier versions of the SNA treated R\&D spending as intermediate consumption. 
Figure 14. Annual growth in bed-days, expenditure per bed-day and total expenditure for mental inpatient care in hospitals, 2005-2015

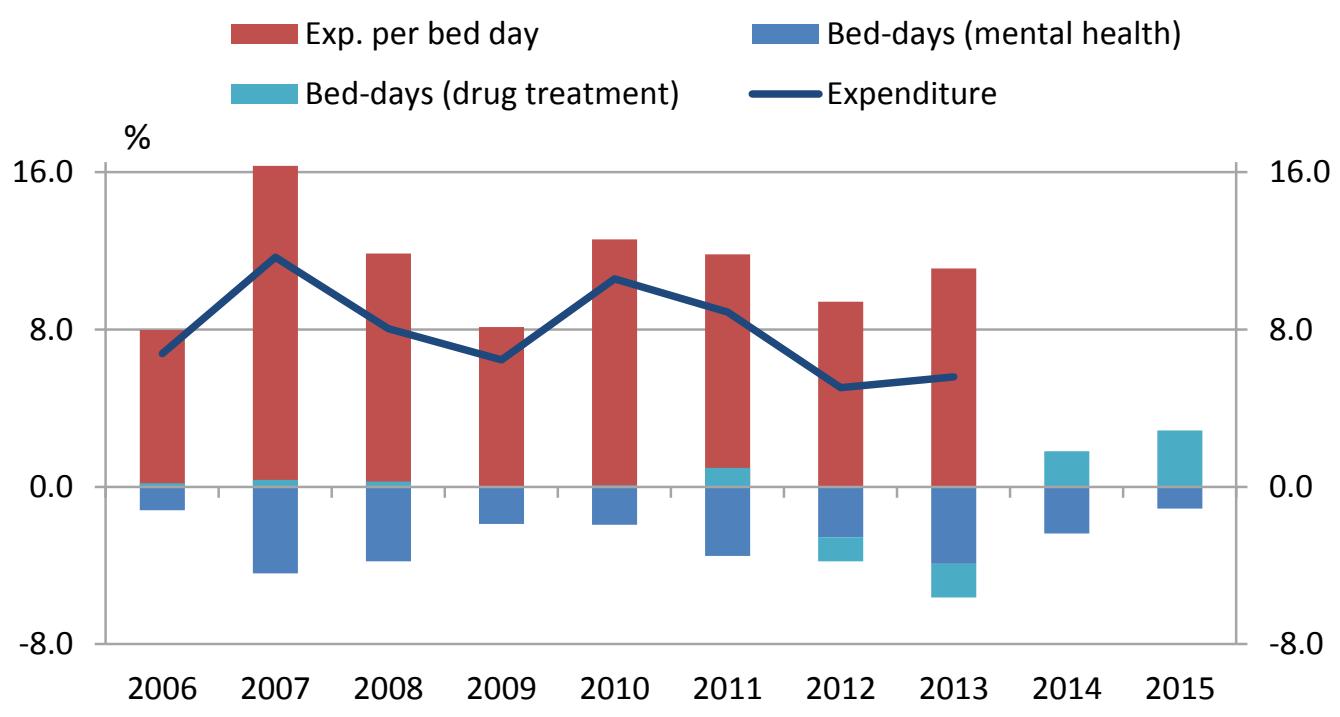

Source: OECD Health Statistics 2016; Statistics Norway Tables 06922, 04511 \&, 04513.

66. In explaining the rise in cost per bed-day for mental health inpatient services, the following questions should be further examined:

- Have cost components in the mental health and substance abuse sector increased differently over the period compared with costs for somatic care?

- Has the increase in costs been due to a change in the intensity of mental health/substance abuse care services provided over the period, due to, for example, a change in case-mix or medical practices?

- Have there been changes in the financing mechanism of mental health hospital care? 
DELSA/HEA/WD/HWP(2017)1

\section{CHAPTER 4. NORWEGIANS PAY A HIGHER PRICE FOR HEALTH CARE}

67. The comparative figures on spending - both at an aggregate level and on the adjusted data on (somatic) hospital inpatient care in the previous two chapters - suggest that health spending in Norway is within the expected range of a high income country and comparable to other high-income countries in Europe with a high public share of health funding in health and LTC. However, it is not clear whether the level of spending in Norway is primarily a result of a high per capita consumption of health care goods and services or whether prices in the health sector are relatively high compared to other countries. This chapter aims to shed light on this by breaking down health and hospital spending into its price and volume components.

\section{High price levels in the Norwegian health sector help explain the level of health spending}

68. Per capita comparisons of health spending (and its various components) presented so far in this study and in other publications such as OECD Health at a Glance are based on data in national currency units converted into a common currency, such as the US dollar (USD), taking into account differences in the purchasing power of national currencies in each country, that is, converted using purchasing power parities (PPPs). PPPs are used in preference to exchange rates in order to take into account the differences in price levels between countries.

69. Economy-wide (GDP) PPPs have typically been used as the most available and reliable conversion rates. However, these are based on a broad basket of goods and services, chosen to be representative of all economic activity. Therefore, the use of economy-wide PPPs means that the resulting variations in health expenditure across countries (as shown in Figure 2) reflect not only variations in the volume of health services, but also any variations in the prices of health services relative to GDP prices, across countries. This is important to bear in mind where countries such as the United States may have relatively low general prices, but high prices in the health sector.

70. PPPs act as being both currency converters and spatial price deflators. When countries share a common currency, as do the countries of the euro area, there is no need to convert to a common currency and they can be defined simply as spatial price deflators. It is important to note that having the same currency does not necessarily mean having the same price level.

71. The problems with collecting or calculating prices in the health sector, where for many countries the majority of the health sector output is the result of non-market production with services provided free or at prices that are not economically significant, have been well-documented. Therefore, any healthspecific PPPs had been traditionally based on input methods that compared salaries of medical and nonmedical staff across countries. Comparing the prices of inputs (the services of staff) is not the same as comparing outputs (the medical services actually delivered) unless the unrealistic assumption holds that productivity of staff is equal across countries. At the same time, previous attempts to use some measure of output prices have typically led to rather spurious results (Melberg, 2011).

72. However, an OECD-Eurostat PPP project (Koechlin et al, 2014) has developed a more robust methodology to produce output-based health (and hospital) PPPs using a common selection of surgical and medical procedures for which "quasi-prices" can be constructed from negotiated or administrative prices or tariffs. As of 2013, this output-based methodology has been used to produce both health and hospital PPPs and which are now incorporated into the overall calculation of GDP PPPs. Both health sector and hospital PPPs are published by Eurostat and OECD. 
73. Comparative price levels or price level indices (PLIs) are the ratios of PPPs to exchange rates and provide a measure of the differences in price levels between countries. Figure 15 compares price level indicators for 2015 by indicating the number of units needed to buy the same volume of services - in this case, across the economy (GDP), the health sector and the hospital sector. The measures are against an average for the countries of the European Union (EU28=100). This means that, for a basket of goods and services across the whole economy which costs 100 units on average, an equivalent basket would cost $44 \%$ more in Norway and 57\% more in Switzerland, etc. All the comparator countries have general price levels above the EU average. In the same way, a basket of health goods and services (which comprises e.g. pharmaceuticals and doctors' consultations in addition to medical procedures) costing 100 units on average across the EU, would be more than double in Switzerland and 88\% higher in Norway. Finally, restricted to a set of comparable hospital services (both inpatient and outpatient), you would need to spend $131 \%$ more in Norway compared with an EU average.

Figure 15. Price level indices (PLI) for GDP, health and hospital services, 2015, EU28=100

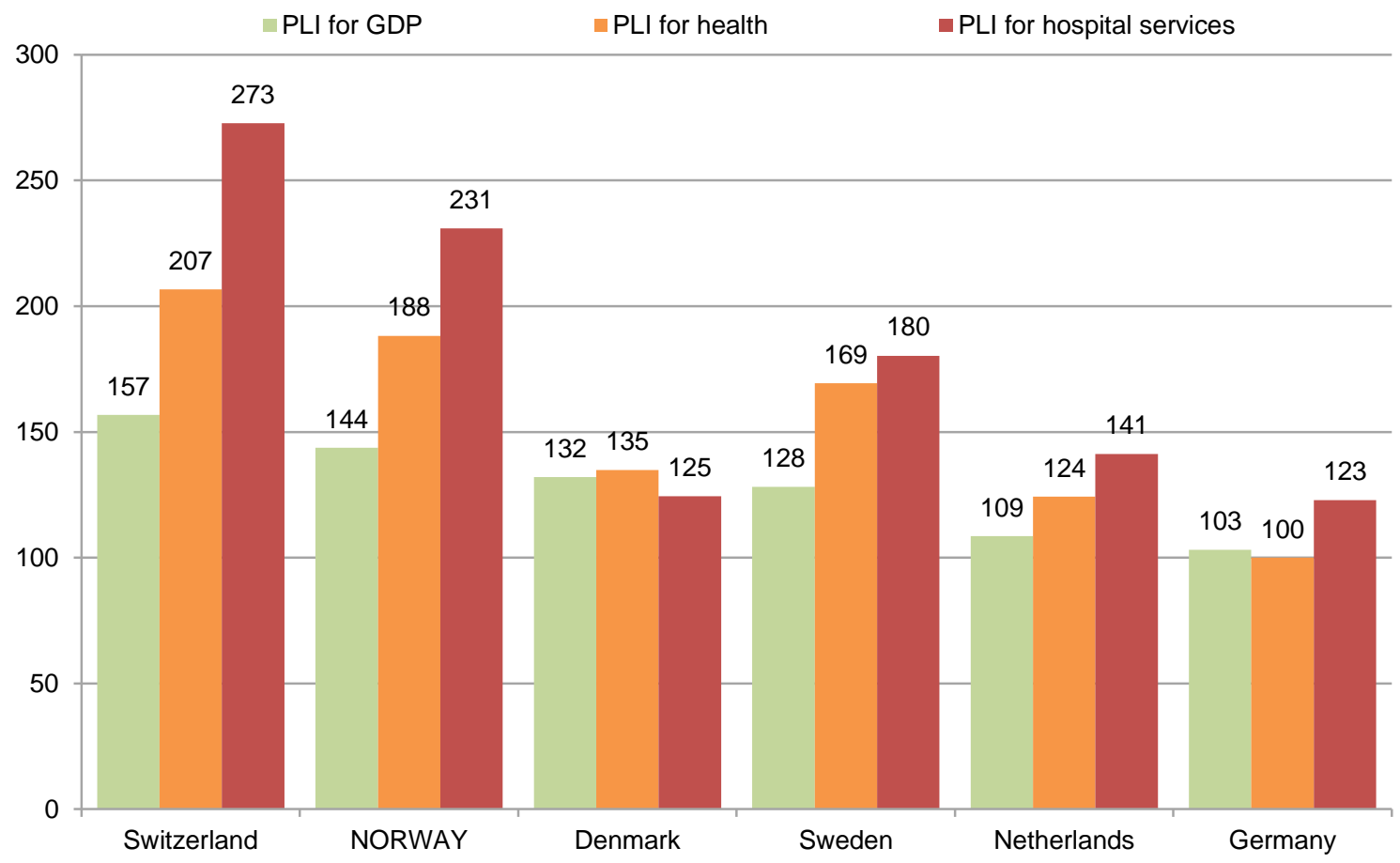

Source: Eurostat, Purchasing power parities (PPPs), price level indices and real expenditures for ESA2010 aggregates.

74. Price levels tend to correlate with income levels: that is, richer countries have generally higher price levels than poorer countries. This correlation is even stronger for services (non-tradable) than for goods (tradable) where national salary levels play a key role. Therefore, in most cases hospital price levels are higher than health price levels which in turn are higher than economy-wide price levels since the health sector is highly labour-intensive (services) but also includes goods, such as pharmaceuticals and therapeutic appliances which are tradable and thus subject to exchange rate and market pressures. For the lower-income EU countries the opposite is generally true with hospital price levels lower than economywide price levels. Among the group of six comparator countries, only Denmark sees relatively lower hospital prices relative to economy-wide prices, which might seem rather surprising. 
75. Figure 15 also shows that even among the group of relatively homogeneous high-income countries, both health and hospital price levels vary more across the countries than price level indices for GDP. In turn, the spread of health price levels is less pronounced than that of hospital price levels.

76. The effect is that comparative prices in the health sector in Norway, Switzerland and Sweden are all 30\% higher than in the rest of the economy, while Denmark and Germany see little difference between the health sector and the economy overall. All countries (except Denmark) then see a widening of the gap in the hospital sector, especially Norway and Switzerland.

77. Dividing per capita health expenditures (and their components) by the respective PPPs gives a measure of the real (i.e. price level adjusted) expenditures or volume of health services consumed. Figure 16 shows the change in the per capita volume of health services if health-specific PPPs rather than economy-wide GDP PPPs are used.

Figure 16. Comparison of per capita volume indices for health, 2015. Norway=100

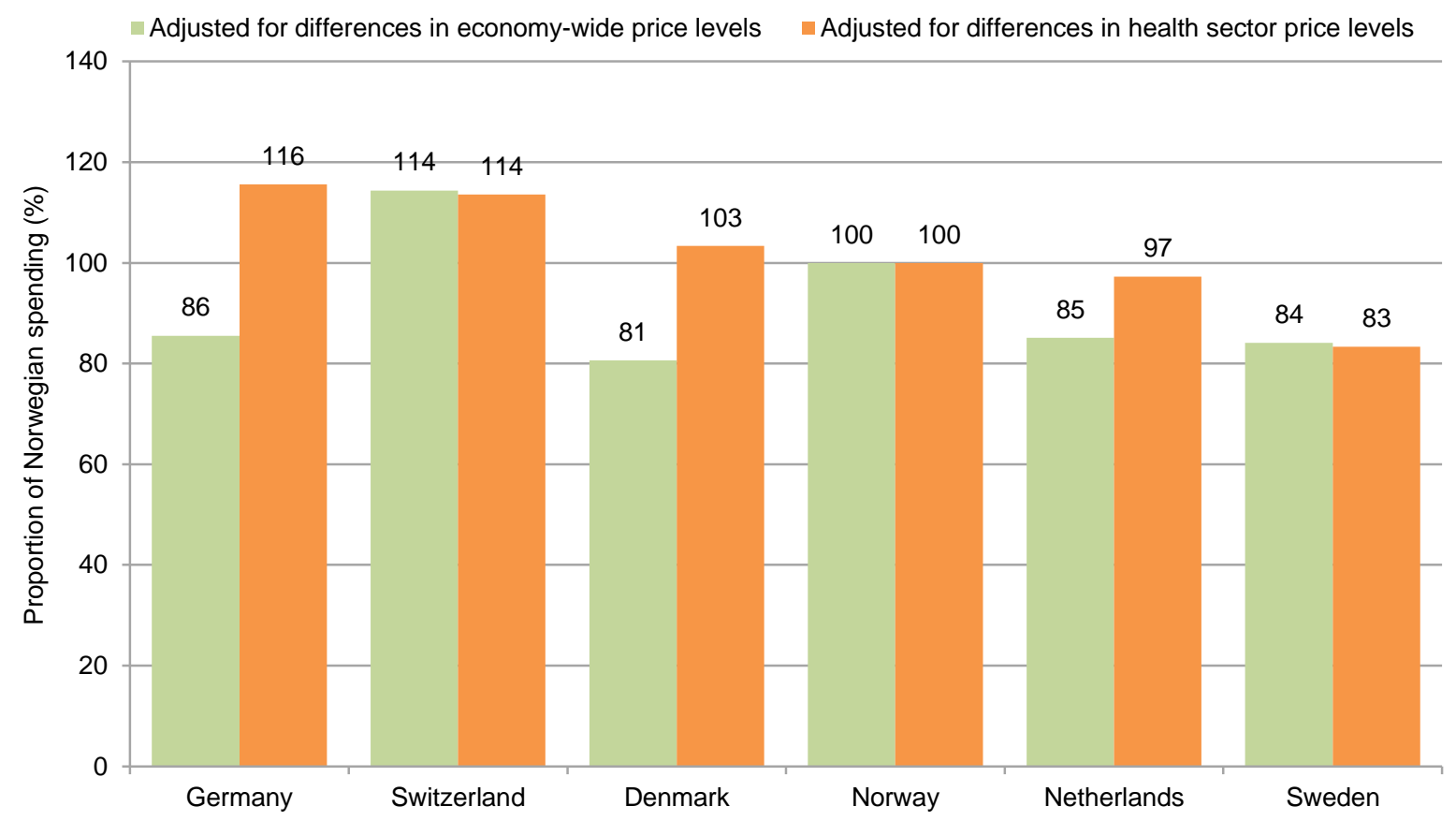

Data adjusted for differences in economy-wide price levels and health sector price levels.

Source: OECD Health Statistics 2016; Eurostat, Purchasing power parities (PPPs), price level indices and real expenditures for ESA2010 aggregates; OECD estimates.

78. Taking Norway as a base (Norway=100), when health-specific prices are taken into account, the relative position of Norway with regards the other comparator countries changes. The narrower difference between the economy-wide and health sector prices in Germany, Netherlands and Denmark means that the deflated health spending increases significantly for these countries, relative to Norway, such that Germany moves to a similar level of health consumption as Switzerland, and low comparative prices in Denmark means that volumes are similar to that of Norway.

79. In summary, when health prices are taken into account, Norway consumes a similar level of health services per capita as Denmark and the Netherlands, more than Sweden but less than Germany and Switzerland. 


\section{Adjusting for high hospital prices means Norwegians consume relatively less}

80. In the same way, using GDP PPPs to deflate hospital spending means that the resulting variations in hospital inpatient spending across countries not only reflect variations in the volume of hospital services, but also any variations in the prices of hospital services relative to economy-wide prices. To obtain a measure of hospital inpatient spending that truly reflects variations in the volume of consumed services, PPPs that are specific to hospital services can be used. The hospital PPPs, available from the already mentioned OECD and Eurostat work on comparative health and hospital price levels, are used to adjust the somatic hospital inpatient spending (as calculated in the previous chapter) for differences in hospital sector price levels.

81. Figure 17 shows the effect of using hospital PPPs rather than GDP PPPs to adjust 2013 somatic hospital inpatient spending for differences in price levels. When accounting for differences in hospital sector price levels (right bar), per capita spending on somatic hospital inpatient care increases for all countries (except Switzerland) relative to Norway compared to spending adjusted for differences in economy-wide price levels (left bar).

Figure 17. Comparison of per capita volume indices for hospital care, 2013. Norway=100

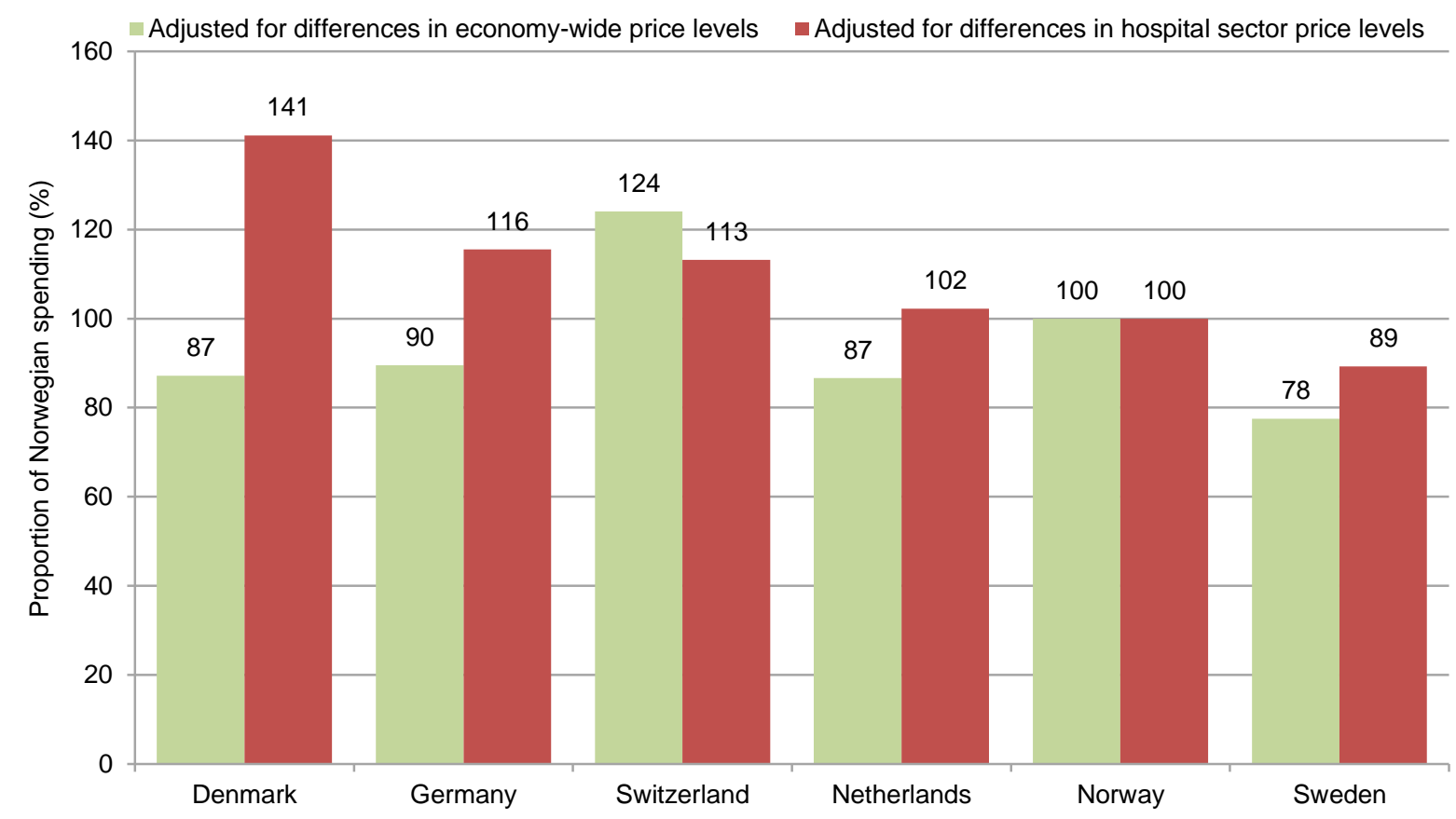

Data adjusted for differences in economy-wide price levels and hospital sector price levels.

Source: 2016 Joint OECD-Eurostat-WHO Health Accounts Questionnaire; OECD Health Statistics 2015; Eurostat, Purchasing power parities (PPPs), price level indices and real expenditures for ESA2010 aggregates; OECD estimates.

82. As explained, while economy-wide price levels in Norway are higher than in the group of comparator countries, hospital sector prices are even higher than in the other countries (except Switzerland). In other words, high hospital sector prices can help explain some of the differences in per capita hospital volumes between Norway and the comparator countries. By consequence, per capita consumption of hospital services in Norway is less than in Denmark, Germany and Switzerland, similar to the Netherlands and higher than in Sweden. 
83. In summary, both health- and hospital-specific output-based PPPs are now published and form part of the overall GDP PPP calculation, but are yet to be extensively used in international comparisons of health and hospital spending. Sector-specific deflators should be used in preference to economy-wide deflators when comparing volumes of health services across countries.

\section{High salaries and staffing levels can help explain higher prices}

84. Measurements and indicators vary in the ease of comparability across countries. Generally, indicators measuring inputs, as opposed to process and outcome aspects, are relatively comparable. For composite indicators, such as DRGs, it is much more difficult to reach a useful level of comparability. Data collection of long time series, equally defined across countries, increases comparability. There are several resource measurements which have been reported for a number of years to OECD and hence allow for a comparison of available resources and their use. These include number of hospital beds, number of physicians available and practicing in the countries, hospital employment, average length of stay, occupancy rates and use of day surgery.

85. As a labour intensive industry, salaries and social contributions are the key cost component in the health sector, and particularly in the hospital sector. Full comparative data of labour costs in the hospital sector across countries are generally not available. The limited data that are available through the health accounts indicate that the share of hospital costs allocated to salaries of staff tends to increase with income. For example, in Hungary and the Czech Republic, remuneration of employees accounted for less than 50\% of total hospital spending, whereas Finland and Canada reported more than $60 \%$ of hospital spending going to salaries and other staff costs. Comparisons can be hampered, however, since this refers only to salaried employees. Where services are contracted out to self-employed physicians or agency nursing personnel, such as in the case of the United States, salaried remuneration as a share of overall hospital costs is low (less than 40\%).

86. Unfortunately, none of the comparator countries provide remuneration data through the SHA data submission, and any figures based on public sources may be difficult to compare for the reasons above. That said, independent data sources ${ }^{14}$ for Denmark, the Netherlands and Norway suggest that salaries and associated costs account for a high proportion of hospital costs in Norway (above 65\%), compared with a lower share in Denmark and the Netherlands. A more extensive examination and comparison would be warranted.

87. A hospital's wage bill is a combination of the remuneration levels of health care (and other nonhealth) professionals as well as the numbers of staff. Data on remuneration levels of salaried physicians and nurses suggest that wage levels in Norway are not excessive - in terms of average wages in the country - when compared to the other countries in this study (OECD, 2015b). For example, remuneration of salaried specialists in Norway was reported as 1.7 times the average wage compared to 2.5 times in Denmark or 2.9 in Germany. Similarly, hospital nurses in Norway earn around the average national wage similar to the situation in Denmark, Germany and the Netherlands. However, comparative salaries are high in Norway. A study during the pilot phase of the Eurostat-OECD PPP project compared the new health output-based results against PPPs based on compensation of employees (physicians, nurses and other nonmedical staff). The corresponding CLIs (for 2010) showed a close alignment between the two indices with Norway showing the highest 'price' in term of 'salaries ${ }^{15}$. Therefore, using PPPs based solely on salaries (akin to an input-based approach) would yield not too dissimilar results to those in Figures 16 and 17 compared with the output-based PPPs.

14. Statistics Denmark, REGR31: Region accounts by region, account, dranst and kind www.statistikbanken.dk/REGR31; Statistics Netherlands: Health care institutions; key figures, finance and personnel; Statistics Norway: Table: 09447: Specialist health services. Expenses incl. health enterprises' own production by type of expenditure, activity and health enterprise.

15. "New methodology for health PPPs" Meeting of the PPP Working Group Doc. 12/P2/06 (Unpublished). 
88. Regarding the second factor, the overall level of staffing by higher level health professionals is also relatively high in Norway, with more than $50 \%$ of employees being either physicians or nurse/midwives (Table 5). Together with the relatively high level of hospital employees per 1000 population this translates into a much higher density of hospital physicians and nurses, compared to Germany and Switzerland.

Table 5. Share of hospital employment (FTE) by type of profession, 2014

\begin{tabular}{|l|c|c|c|c|c|}
\hline Share of hospital employment (\%) & Denmark & Germany & Netherlands & Norway & Switzerland \\
\hline Physicians & 14.3 & 16.4 & 10.7 & 12.9 & 13.0 \\
\hline Nurses/Midwives & 34.8 & 38.0 & 26.3 & 41.5 & 30.4 \\
\hline Associate nurses & 8.6 & 4.5 &.. & 0.0 & 4.6 \\
\hline Healthcare assistants & 1.3 &.. & 5.6 & 8.5 & 7.3 \\
\hline Other health professionals & 11.0 & 17.1 & \multirow{2}{*}{57.4} & 15.3 & 13.9 \\
\cline { 1 - 5 } Other hospital employees & 30.0 & 24.3 & & 21.9 & 30.8 \\
\hline Hospital employees/1000 pop. & $\mathbf{1 8 . 9}$ & $\mathbf{1 1 . 9}$ & $\mathbf{1 2 . 8}$ & $\mathbf{1 8 . 0}$ & $\mathbf{1 8 . 7}$ \\
\hline
\end{tabular}

Data for Denmark refer to 2013.

Source: OECD Health Statistics 2016.

89. Caution is needed in interpretation though, for several reasons. Relatively easily measured and compared indicators often lack the ability to capture complex structures. Staff resources represent only one of the main cost drivers in health, but the skills-mix has large implications for the cost and efficiency of providers. Staff categories other than physicians are difficult to compare, not only in terms of education and responsibilities. The differences in skills-mix, use of team work, and patient pathways make input indicators like staff numbers difficult to compare across countries. Also, with increasing use of advanced drugs and technology for certain types of treatment, indicators of physical resources are generally more difficult to compare.

90. The number of hospital beds as an indicator of structural costs in delivering hospital services is an objective measurement with a relatively stable methodology which allows for international comparisons. Sweden and Denmark allocate less physical resources in the hospital sector with fewer beds per 1000 population. Norway has a relatively low number of somatic curative beds while the number of psychiatric beds is high (Figure 18). 
Figure 18. Hospital beds per 1000 population, 2013 (or nearest year)

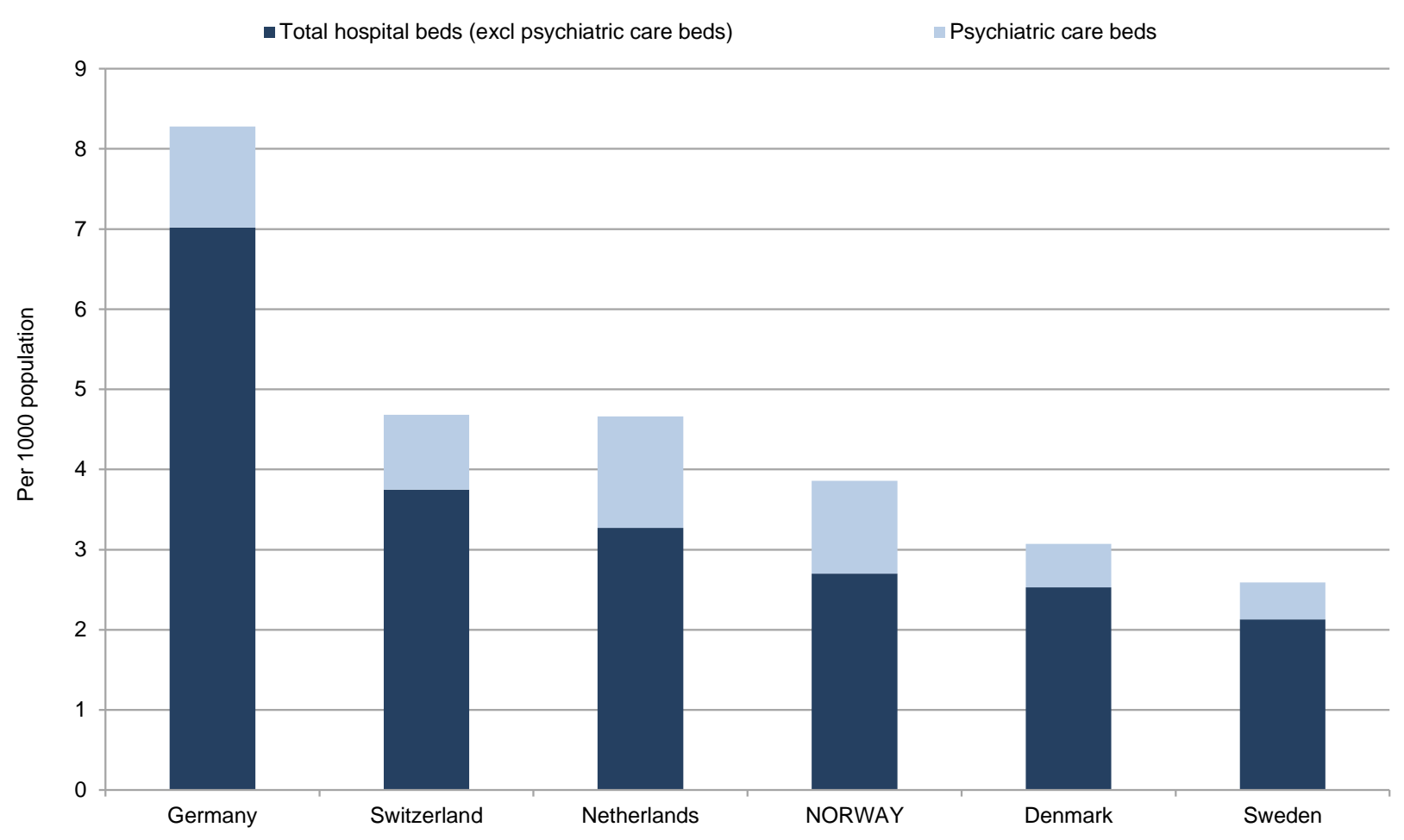

Source: OECD Health Statistics 2016.

91. While there has been a general decrease in the number of beds across Europe, the pace of downsizing varies. While the trend data on hospital beds prior to the 2002 administrative reform in Norway makes it difficult to compare earlier years, only Denmark has since reduced the number of beds more than Norway. Generally, Germany and the Netherlands have maintained their bed numbers over recent decades to a larger degree, contributing to their high capacity. Sweden had already decreased its hospital beds considerably more than other countries in the 1990s. This was across all types of services, but especially in psychiatry, due to a major policy change in psychiatric care, which lead to the closing of several hospitals.

\section{Long lengths of stay in Germany and Switzerland can help explain high volumes}

92. This section looks at hospital discharges and average length of stay (ALOS) as a way to examine differences in hospital activity across countries. Overall the figures (Figures 19 and 20) appear to support the differences in per capita volumes of consumed hospital services suggested in Figure 17. Germany, for example, has considerably higher hospital discharge rates than Norway as well as ALOS, and, while Switzerland has relatively low hospital discharge rates, the average length of stays are significantly high. On the other hand, Sweden has somewhat lower hospital discharge rates and shorter ALOS compared to Norway. For Denmark the picture appears to be more mixed. While Figure 17 suggests a relatively highvolume (and low-price) hospital sector in Denmark, hospital activity as indicated by hospital discharges and ALOS in itself seems to be relatively low. This would require further investigation.

93. OECD Health Statistics also allows for a comparison in the volume of discharges across countries for the main diagnosis groups. While the available breakdowns show considerable differences in the hospital case-mix between countries, they also provide a measure of the overall volume of services 
provided for the hospital resources available. For the major somatic diagnosis groups: neoplasms, circulatory, respiratory, digestive and musculoskeletal diseases, Norway has total volumes comparable to, or higher than, neighbouring Nordic countries and Switzerland, although with differences between the areas of care. Only Germany has a considerable higher number of discharges, in line with the high-volume expenditure suggested (Figure 19).

Figure 19. Curative care discharges for selected diagnose groups per 1000 population, 2014

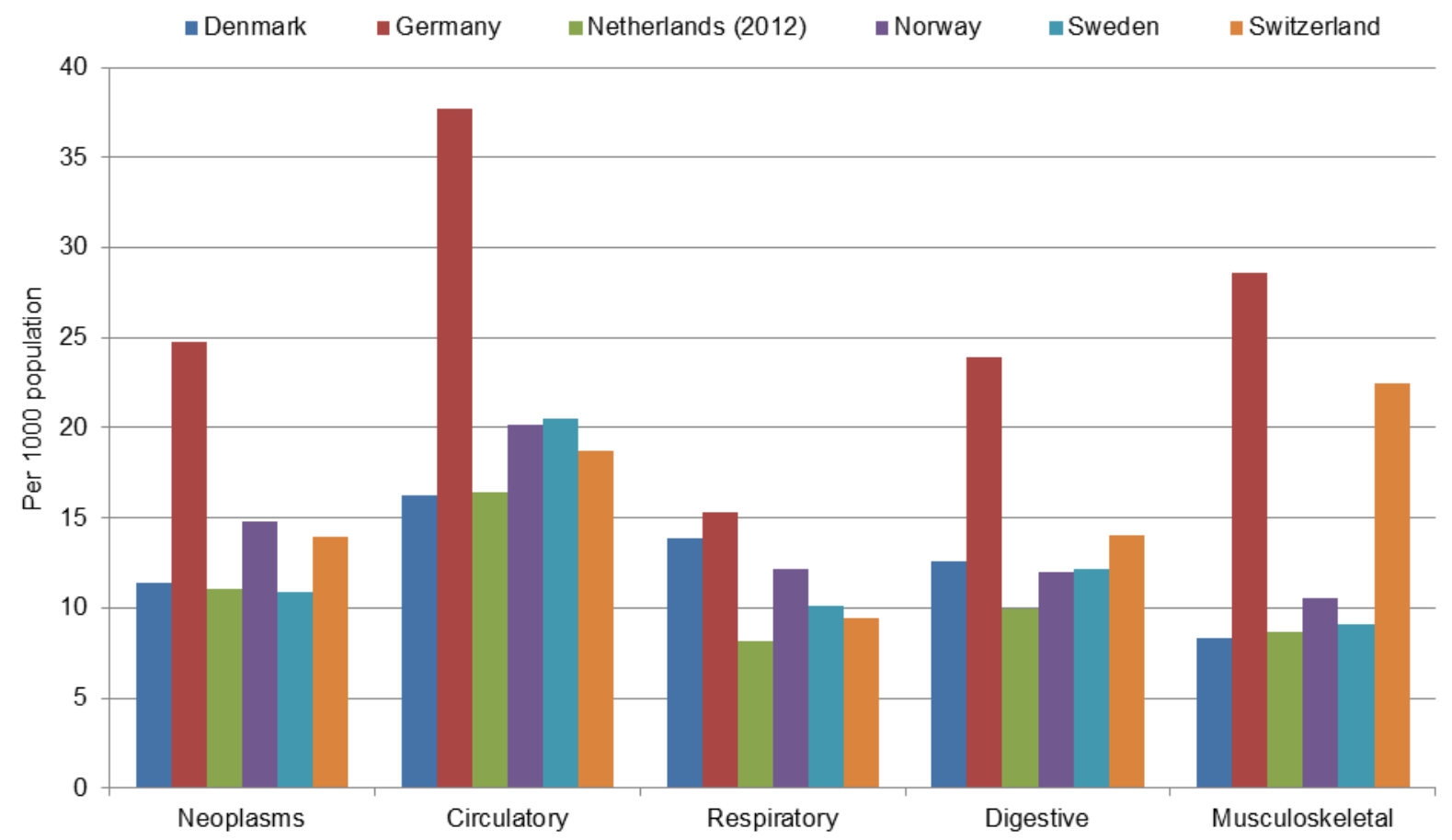

Source: OECD Health Statistics 2016.

94. The SAMDATA reports (Helsedirektoratet, 2016) ${ }^{16}$ describe increased service volumes in Norwegian health care since 2010, with polyclinic services being the main driver. For hospital services though, the volumes, as measured in DRG-points, have increased considerably but decreased as measured in terms of bed-days, with differences across age groups, diagnoses and type of care. The development generally follows the same pattern in all OECD countries, which is explained by a continued shift in treatment profiles towards outpatient care for many diagnoses. The overall efficiency of the health system improves when inpatient hospital services are restricted to the more advanced and complex cases and treatments, while an increase in volume of services takes place in polyclinics. In the cost data presented in SAMDATA this results in increasing costs per bed-night and declining costs per DRG-point (up until 2015).

95. Like most other countries, the average length of stay (ALOS) in Norwegian hospitals has been falling for several decades, due to both advances in medical technology, resource awareness and changes in incentives through the reimbursement systems and regulations. The SAMDATA report describes a general decrease in ALOS from 4.7 to 4.3 days between 2010 and 2015, with some variation across the country in absolute number of days and degree of reduction. ALOS for a selection of treatments also show differences

16. Annual report on developments in resource allocation, use of services and use of resources for both somatic treatment, mental health care and interdisciplinary specialized substance abuse treatment (TSB). 
in reduction between areas of care, with hip replacements and hip fractures showing the largest decrease while other more complex treatments like cancer and bypass surgery changed relatively less. The largest single factor for the reduction, in addition to the general trend, is the relative shift in funding responsibility, which took place in 2012. Municipalities are now carrying the cost for patients whose discharges are delayed. Consequently, most of the reduction takes place among older patients for this period.

96. While all countries have decreased ALOS, there are still considerable differences among European countries, with a distinctive difference between Scandinavian countries and continental Europe. For diseases in the circulatory system and digestive system, Norway has the lowest ALOS of the countries compared in this report (Figure 20).

Figure 20. Comparison of ALOS for selected diagnose groups, 2014

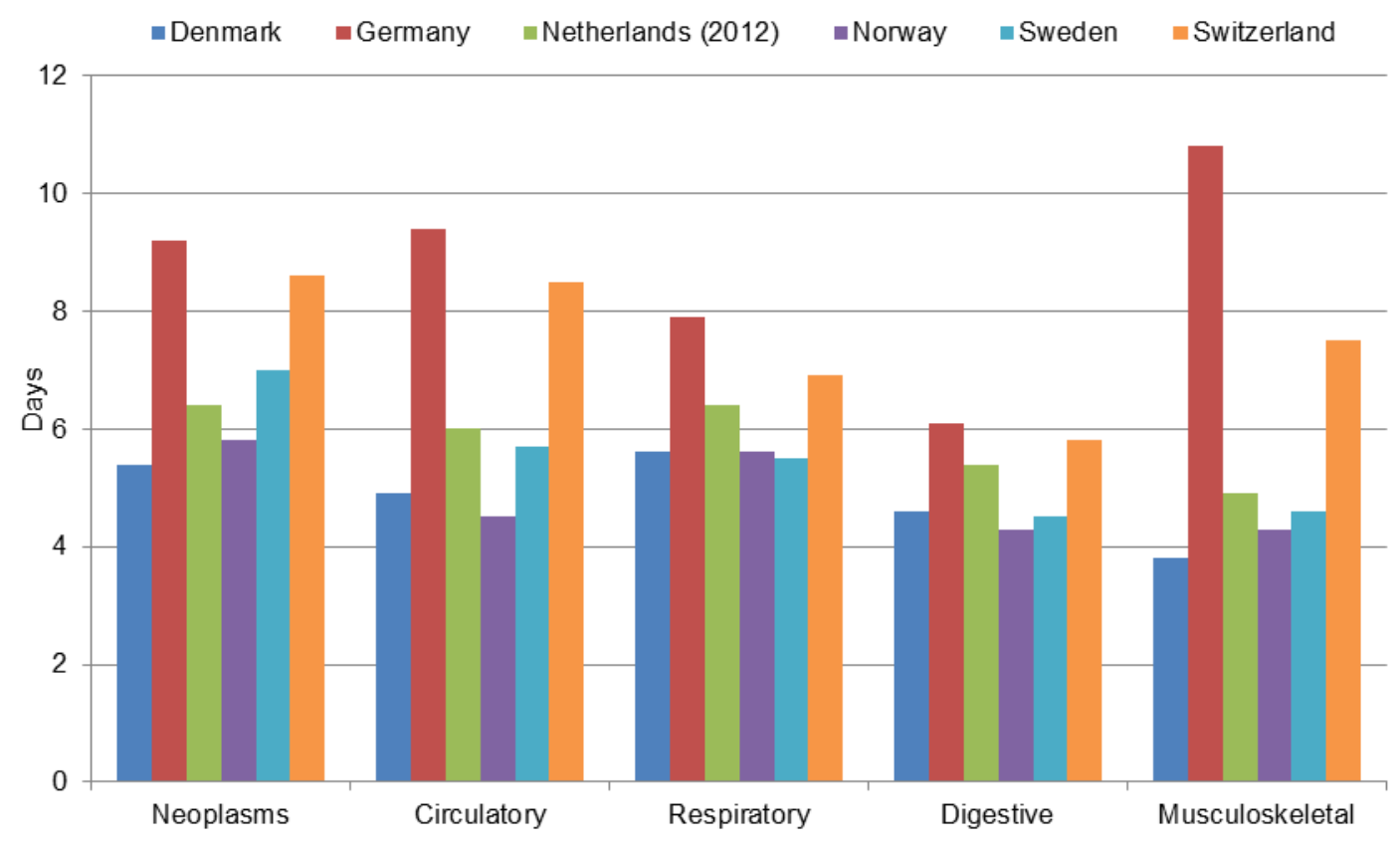

Source: OECD Health Statistics 2016.

97. The reduction over time is very much dependent on the starting point and changes in the national health system at large. As such, there are significant differences in the dynamics of ALOS between countries (Table 6).

98. The number of ALOS naturally correlates with the number of available beds in the system, which has a similar pattern across the countries. To achieve gains in system-wide efficiency, fewer days in hospital per patient have to be managed with the available resources. In addition to low ALOS, Norway also has a relatively high occupancy rate according to OECD data. Of the 24 reporting countries in the OECD database, Norway's $91 \%$ occupancy rate is the third highest. There is no comparable data available for Sweden and Denmark, but the continental European countries have considerably lower occupancy rates, indicating that Norway makes good use of its hospital structural costs. 
Table 6. Comparison of ALOS reduction for selected diagnose groups, 2004-2014

\begin{tabular}{|l|r|r|r|r|r|r|}
\hline & \multicolumn{1}{|c|}{ Denmark } & Germany & Netherlands* & \multicolumn{1}{c|}{ Norway } & \multicolumn{1}{c|}{ Sweden } & \multicolumn{1}{c|}{ Switzerland } \\
\hline Neoplasms & $-22.9 \%$ & $-12.4 \%$ & $-27.3 \%$ & $-20.5 \%$ & $-13.6 \%$ & $-11.3 \%$ \\
\hline Circulatory & $-26.9 \%$ & $-11.3 \%$ & $-25.9 \%$ & $-18.2 \%$ & $-13.6 \%$ & $-5.6 \%$ \\
\hline Respiratory & $-6.7 \%$ & $-13.2 \%$ & $-17.9 \%$ & $-9.7 \%$ & $-1.8 \%$ & $-16.9 \%$ \\
\hline Digestive & $-16.4 \%$ & $-21.8 \%$ & $-22.9 \%$ & $-12.2 \%$ & $-8.2 \%$ & $-14.7 \%$ \\
\hline Musculoskeletal & $-44.1 \%$ & $-18.8 \%$ & $-29.0 \%$ & $-15.7 \%$ & $-29.2 \%$ & $-15.7 \%$ \\
\hline
\end{tabular}

* 2012, Source: OECD Health Statistics 2016.

99. As with most indicators which are relatively easy to measure, caution is warranted, which is also highlighted in the SAMDATA report. Reduced ALOS was considered a clear-cut indicator of hospital efficiency when it was introduced. But over time several concerns have been raised that the indicator is insensitive to wider system efficiency and quality. Leaving the hospital early does not necessarily lead to higher system efficiency if other providers, or family, have to take a dis-proportionate share of the care burden. Furthermore, aspects of quality of care should be considered, as there is a risk of re-admission if the patient is discharged too early.

\section{Norway's use of day surgery as a way to reduce costs is relatively low}

100. The use of day surgery is an area of debate in Norway and the development in this area a major topic of the SAMDATA reporting. The use of day surgery has on average decreased marginally between 2010 and 2013, contrary to what might be expected with the developments in medical technology, although the trend varies depending on the area of care. From 2014 it has however increased significantly, possibly in response to changed incentives.

101. Until 2010, Norwegian DRG-weights did not reflect the differences in cost structure between traditional surgery and day surgery. This meant a strong incentive to develop day surgery practices. From 2010 DRG-weights for day surgery and traditional surgery were separated to reflect their respective cost structure, to avoid reimbursing hospitals for inpatient surgery costs when they provided day surgery. This removed the hospitals' incentives to perform day surgery and has raised debates about Norway not taking advantage of new technology and procedures to the extent possible. From 2015 the weights are again changed.

102. Norway's use of day surgery is considerably lower than in its neighbouring countries. Figure 21 displays day surgery as a share of all surgery for the procedures reported to OECD. These treatments are selected to describe the use of day surgery because they represent the largest number of cases reported to OECD. Their share of total hospital costs is however limited and cannot explain variation in total hospital spending. With the exception of cataract surgery, Germany and Switzerland stand out with a restrictive use of day surgery. The variation among the remaining four countries is large. Nevertheless, Norway does not have a top position in the practice of day surgery and falls behind both Sweden and Denmark in five of the selected treatments. This gives room for improvement in the overall efficiency of hospital surgery with more output for the resources spent ${ }^{17}$.

17. For a comparison with the Swedish and British development, see: http://www.lakartidningen.se/Opinion/Debatt/2016/01/Storutvecklingspotential-med-dagkirurgi/ 
Figure 21. Proportion of procedures performed as day surgery for selected surgeries, 2014 (or nearest year)

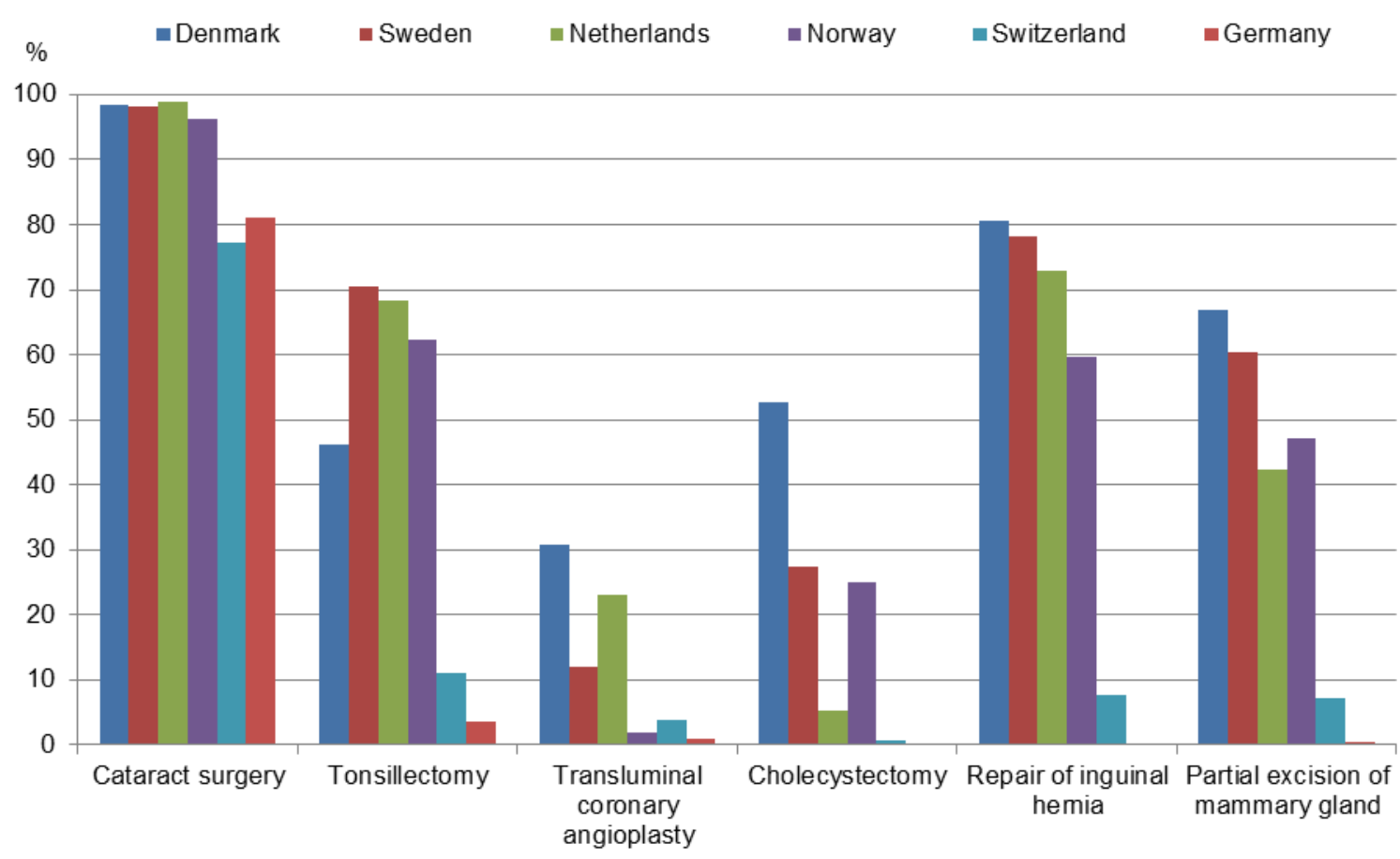

Source: OECD Health Statistics 2016.

103. In summary, among the group of comparator countries, Norway and Switzerland show high prices in the health and particularly the hospital sector. High relative salaries together with a greater density of staff providing hospital services helps to explain the higher prices in Norway. Deflating spending using health-specific PPPs suggests that per capita consumption of health (hospital) services is lower than, for example, Germany and Switzerland. Additional data on hospital activities and length of stay go some way to confirming this finding. 


\section{CHAPTER 5. DISCUSSION}

104. This study explains the level of health spending in Norway relative to other high-income countries by describing the components of health care spending and separating expenditures into volumes and prices. This provides a base of information for a financial analysis of how resources are used to produce outputs by the health system. The extent to which these outputs are effectively translated into the quality of services and outcomes is however beyond the scope of this report. While a cross-country comparison of a set of quality and outcome indicators shows the Norwegian health system as ranking high internationally (OECD, 2015), the analysis presented in this report suggests that further work on quality of care and outcomes would be useful, especially for those areas which are relatively costly or resourcedemanding

105. The analysis suggests that per capita spending in Norway, adjusted for differences in general price levels, is higher than in most of the comparator countries but is generally in line with the economic and demographic profile. Similarly, the extent of spending on long-term care would seem to align with the wealth, dependency level and need for formal care in Norway, resulting in the highest percentage of health spending allocated to LTC. A more detailed modelling of the effects of each of these factors could provide further insights into the role of each in the determination of the level of spending across the comparator countries.

106. The disparity between a highly-ranked per capita health spending measure and only average health spending as a share of GDP has been shown to be due to some of the particularities of the Norwegian economy. The level of health spending is somewhat independent of the overall level of resources meaning that a fall in oil revenues in recent years has resulted in a significantly higher share of GDP allocated to health without a change in the overall trend in health spending. For the same reason, the observation is not restricted to the health sector. Large societal resources lead to high levels of spending per capita also in other sectors (e.g. education), but moderate levels of spending as a share of GDP. It is more important to note that relative to other sectors of public responsibility, Norway allocates resources to health on a level comparable to other Nordic countries.

107. The study also shows that estimates of inpatient care differ across countries in terms of their coverage (e.g. the inclusion of day care) and service organisation (e.g. the degree of mental health/substance abuse care included) and that additional data sources and assumptions can allow for a better understanding of somatic hospital care. Such methodological information is important in making meaningful comparisons.

108. High health- and hospital-specific comparative price levels in Norway (and Switzerland) appear to be driven by the higher salary and staffing levels, which in turn explain the overall levels of hospital spending. However, further sensitivity analysis is needed to ascertain whether comparative price levels are over- and under-estimated in e.g. Norway and Denmark, respectively, due to the weighting of specific procedure prices or systemic errors in the methodology.

109. Given the possible limitations in hospital price estimates, the differences in hospital volumes can be partially explained using additional data on hospital activities. Further work on comparable hospital statistics (e.g. SAMDATA) for the group of countries would allow for a more detailed analysis of hospital volumes and prices. 


\section{REFERENCES}

Anderson GF, PS Hussey, BK Frogner and HR Waters (2005), 'Health Spending In The United States And The Rest Of The Industrialized World', Health Affairs, July 2005 vol. 24 no. 4903-914.

Belloni, A., D. Morgan and V. Paris (2016), "Pharmaceutical Expenditure And Policies: Past Trends And Future Challenges", OECD Health Working Papers, No. 87, OECD Publishing, Paris. DOI: http://dx.doi.org/10.1787/5jm0q1f4cdq7-en

de la Maisonneuve, C. et J. Oliveira Martins (2013), « A Projection Method for Public Health and LongTerm Care Expenditures », OECD Economics Department Working Papers, No. 1048, OECD Publishing, Paris.

DOI : http://dx.doi.org/10.1787/5k44v53w5w47-en

EC, IMF, OECD, UN and World Bank (2009), 'System of National Accounts 2008', European Commission, International Monetary Fund, Organisation for Economic Co-operation and Development, United Nations and World Bank, New York, Dec. 2009.

Helsedirektoratet (2015), 'SAMDATA: Spesialisthelsetjenesten 2014'.

Helsedirektoratet (2016), 'SAMDATA: Spesialisthelsetjenesten 2015'.

Hostenkamp G (2011), 'The Market for Hospital Medicine in Denmark', Nordic Journal of Health Economics, [S.1.], v. 1, n. 1, Nov. 2011.

Ke X., P. Saksena and A. Holly (2011), 'The Determinants of Health Expenditure: A Country-Level Panel Data Analysis', Working Paper of the Results for Development Institute (R4D), WHO, Geneva.

Koechlin, F., et al. (2014), "Comparing Hospital and Health Prices and Volumes Internationally: Results of a Eurostat/OECD Project", OECD Health Working Papers, No. 75, OECD Publishing, Paris. DOI: http://dx.doi.org/10.1787/5jxznwrj32mp-en

Lorenzoni L, A Belloni and F Sassi (2014), 'Health-care expenditure and health policy in the USA versus other high-spending OECD countries', The Lancet, July 2014, Vol. 384: 83-92.

Lorenzoni, L., et al. (2015), "Public Expenditure Projections for Health and Long-Term Care for China Until 2030", OECD Health Working Papers, No. 84, OECD Publishing, Paris.

DOI: http://dx.doi.org/10.1787/5jrs3c274vq3-en

McPherson, K., G. Gon and M. Scott (2013), "International Variations in a Selected Number of Surgical Procedures", OECD Health Working Papers, No. 61, OECD Publishing, Paris.

DOI: http://dx.doi.org/10.1787/5k49h4p5g9mw-en

Melberg H. O. (2011), 'Some problems with international comparisons of health spending', Health Economics Research Programme, Working paper 2011: 4, University of Oslo.

Morgan, D. et R. Astolfi (2013), « Health Spending Growth at Zero : Which Countries, Which Sectors Are Most Affected? », OECD Health Working Papers, No. 60, OECD Publishing, Paris.

DOI : http://dx.doi.org/10.1787/5k4dd1st95xv-en 
Morgan, D. and R. Astolfi (2014), "Health Spending Continues to Stagnate in Many OECD Countries", OECD Health Working Papers, No. 68, OECD Publishing, Paris.

DOI: http://dx.doi.org/10.1787/5jz5sq5qnwf5-en

OECD (2015a), Fiscal Sustainability of Health Systems: Bridging Health and Finance Perspectives, OECD Publishing, Paris.

DOI: http://dx.doi.org/10.1787/9789264233386-en

OECD (2015b), Health at a Glance 2015: OECD Indicators, OECD Publishing, Paris. DOI: http://dx.doi.org/10.1787/health_glance-2015-en

OECD/WHO/Eurostat (2011), A System of Health Accounts: 2011 Edition, OECD Publishing, Paris. DOI: http://dx.doi.org/10.1787/9789264116016-en 


\section{OECD HEALTH WORKING PAPERS}

A full list of the papers in this series can be found on the OECD website: http://www.oecd.org/els/health-systems/health-workingpapers.htm

No. 90 HOW OECD HEALTH SYSTEMS DEFINE THE RANGE OF GOOD AND SERVICES TO BE FINANCED COLLECTIVELY (2016)

Ane Auraaen1, Rie Fujisawa1, Grégoire de Lagasnerie1, Valérie Paris

No. 89 THE ORGANISATION OF OUT-OF-HOURS PRIMARY CARE IN OECD COUNTRIES (2016)

Caroline Berchet, Carol Nader

No. 88 HEALTH CARE COVERAGE IN OECD COUNTRIES IN 2012 (2016) Valérie Paris, Emily Hewlett, Ane Auraaen, Jan Alexa, Lisa Simon

No. 87 PHARMACEUTICAL EXPENDITURE AND POLICIES: PAST TRENDS AND FUTURE CHALLENGES (2016) Annalisa Belloni, David Morgan, Valérie Paris

No. 86 THE LABOUR MARKET IMPACTS OF OBESITY, SMOKING, ALCOHOL USE AND RELATED CHRONIC (2016) Marion Devaux, Franco Sassi

No. 85 INTERNATIONAL COMPARISON OF SOUTH AFRICAN PRIVATE HOSPITALS PRICE LEVELS (2015) Luca Lorenzoni, Tomas Roubal

No. 84 PUBLIC EXPENDITURE PROJECTIONS FOR HEALTH AND LONG-TERM CARE FOR CHINA UNTIL 2030 (2015) Luca Lorenzoni, David Morgan, Yuki Murakami and Chris James*

No. 83 EMERGENCY CARE SERVICES: TRENDS, DRIVERS AND INTERVENTIONS TO MANAGE THE DEMAND (2015) Caroline Berchet

No. 82 MENTAL HEALTH ANALYSIS PROFILES (MhAPs) Sweden (2015) Pauliina Patana

No. 81 MENTAL HEALTH ANALYSIS PROFILES (MhAPs) England (2015) Emily Hewlett and Kierran Horner

No. 80 ASSESSING THE IMPACTS OF ALCOHOL POLICIES (2015) Michele Cecchini, Marion Devaux, Franco Sassi

No. 79 ALCOHOL CONSUMPTION AND HARMFUL DRINKING: TRENDS AND SOCIAL DISPARITIES ACROSS OECD COUNTRIES (2015) Marion Devaux and Franco Sassi

No. 78 TAPERING PAYMENTS IN HOSPITALS - EXPERIENCES IN OECD COUNTRIES (2015) Grégoire de Lagasnerie, Valérie Paris, Michael Mueller, Ankit Kumar

No. 77 WAGE-SETTING IN THE HOSPITAL SECTOR (2014) James Buchan, Ankit Kumar, Michael Schoenstein

No. 76 HEALTH, AUSTERITY AND ECONOMIC CRISIS: ASSESSING THE SHORT-TERM IMPACT IN OECD COUNTRIES (2014) Kees van Gool and Mark Pearson

No. 75 COMPARING HOSPITAL AND HEALTH PRICES AND VOLUMES INTERNATIONALLY (2014) Francette Koechlin, Paul Konijn, Luca Lorenzoni, Paul Schreyer 


\section{RECENT RELATED OECD PUBLICATIONS}

OECD REVIEWS OF HEALTH SYSTEMS: LATVIA 2016

HEALTH AT A GLANCE: EUROPE (2016)

HEALTH AT A GLANCE: ASIA/PACIFIC (2016)

BETTER WAYS TO PAY FOR HEALTH CARE (2016)

HEALTH WORKFORCE POLICIES IN OECD COUNTRIES: RIGHT JOBS, RIGHT SKILLS, RIGHT PLACES (2016)

OECD REVIEWS OF HEALTH CARE QUALITY: UNITED KINGDOM (2016)

OECD REVIEWS OF HEALTH SYSTEMS: MEXICO (2016)

OECD REVIEWS OF HEALTH SYSTEMS: COLOMBIA (2015)

HEALTH AT A GLANCE (2015)

HEALTH DATA GOVERNANCE: PRIVACY, MONITORING AND RESEARCH (2015)

FISCAL SUSTAINIBILITY OF HEALTH SYSTEMS: BRIDGING HEALTH AND FINANCE PERSPECTIVES (2015) OECD HEALTH STATISTICS (2016) (database available from http://www.oecd.org/health/healthdata)

ADDRESSING DEMENTIA - THE OECD RESPONSE (2015)

CARDIOVASCULAR DISEASE AND DIABETES - POLICIES FOR BETTER HEALTH AND QUALITY OF CARE (2015)

DEMENTIA RESEARCH AND CARE: CAN BIG DATA HELP? (2015)

FIT MIND, FIT JOB - FROM EVIDENCE TO PRACTICE IN MENTAL HEALTH AND WORK (2015)

TACKLING HARMFUL ALCOHOL USE - ECONOMICS AND PUBLIC HEALTH POLICY (2015)

MAKING MENTAL HEALTH COUNT: THE SOCIAL AND ECONOMIC COSTS OF NEGLECTING MENTAL HEALTH CARE (2014)

GEOGRAPHIC VARIATIONS IN HEALTH CARE: WHAT DO WE KNOW AND WHAT CAN BE DONE TO IMPROVE HEALTH SYSTEM PERFORMANCE? (2014)

PAYING FOR PERFORMANCE IN HEALTH CARE: IMPLICATIONS FOR HEALTH SYSTEM PERFORMANCE AND ACCOUNTABILITY (2014)

OBESITY HEALTH UPDATE (2014)

HTTP://WWW.OECD.ORG/ELS/HEALTH-SYSTEMS/OBESITY-UPDATE-2014.PDF (ELECTRONIC FORMAT $O N L Y)$

OECD REVIEWS OF HEALTH CARE QUALITY: AUSTRALIA (2015)

OECD REVIEWS OF HEALTH CARE QUALITY - JAPAN (2015)

OECD REVIEWS OF HEALTH CARE QUALITY - ITALY (2015)

OECD REVIEWS OF HEALTH CARE QUALITY - PORTUGAL (2015)

OECD REVIEWS OF HEALTH CARE QUALITY - CZECH REPUBLIC (2014)

OECD REVIEWS OF HEALTH CARE QUALITY - NORWAY (2014)

For a full list, consult the OECD iLibrary at http://www.oecd-ilibrary.org/ 